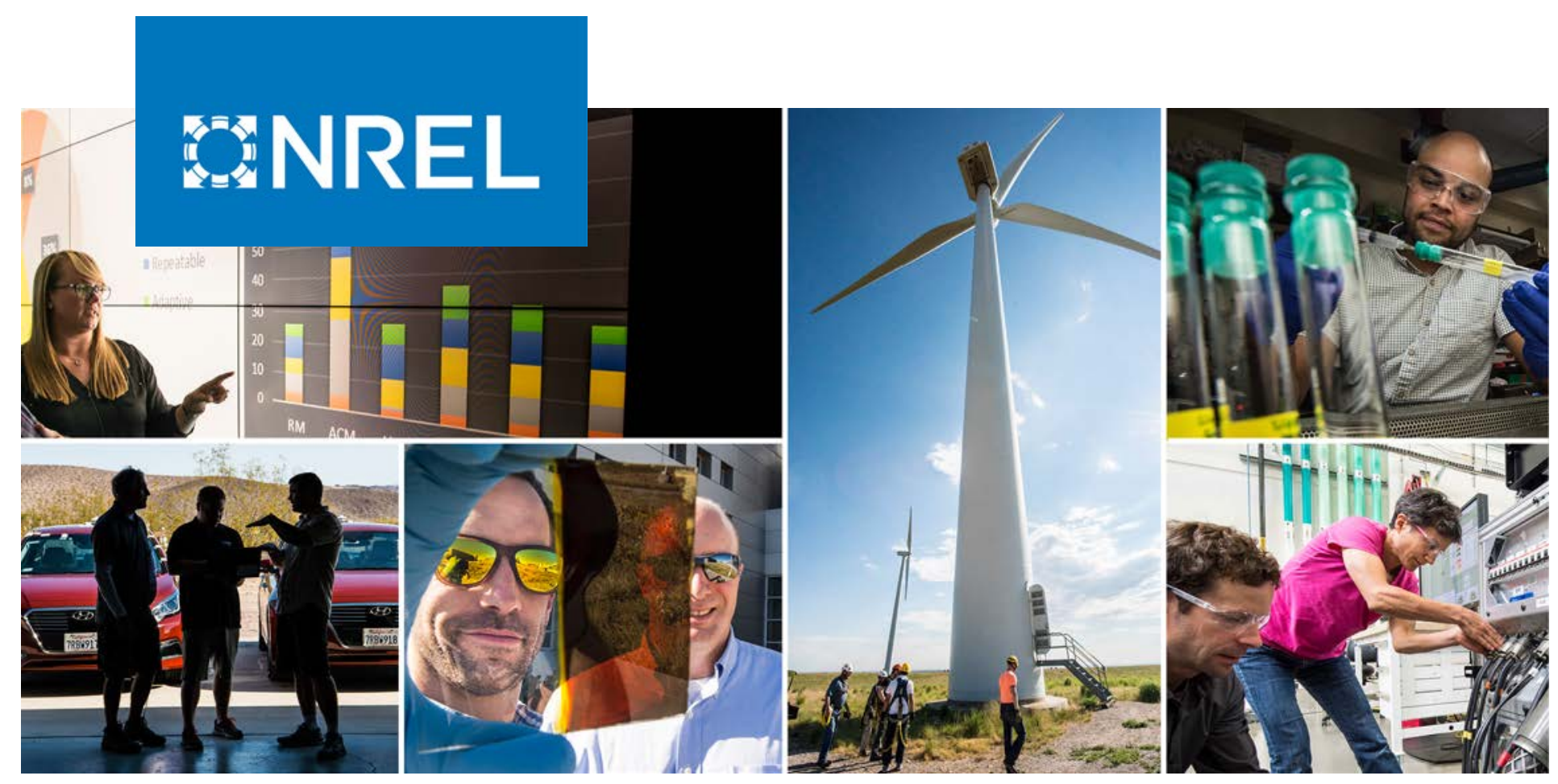

\title{
A Guide to Updating Interconnection Rules and Incorporating IEEE Standard 1547
}

Michael Ingram, Akanksha Bhat, and David Narang

National Renewable Energy Laboratory

NREL is a national laboratory of the U.S. Department of Energy

Office of Energy Efficiency \& Renewable Energy

Operated by the Alliance for Sustainable Energy, LLC

This report is available at no cost from the National Renewable Energy Laboratory (NREL) at www.nrel.gov/publications.
Technical Report

NREL/TP-5D00-75290

October 2021 


\section{GNREL}

\section{A Guide to Updating Interconnection Rules and Incorporating IEEE Standard 1547}

Michael Ingram, Akanksha Bhat, and David Narang

National Renewable Energy Laboratory

\section{Suggested Citation}

Ingram, Michael, Akanksha Bhat, and David Narang. 2021. A Guide to Updating Interconnection Rules and Incorporating IEEE Standard 1547. Golden, CO: National Renewable Energy Laboratory. NREL/TP-5D00-75290.

https://www.nrel.gov/docs/fy22osti/75290.pdf.

NREL is a national laboratory of the U.S. Department of Energy Office of Energy Efficiency \& Renewable Energy Operated by the Alliance for Sustainable Energy, LLC

This report is available at no cost from the National Renewable Energy Laboratory (NREL) at www.nrel.gov/publications.

Contract No. DE-AC36-08GO28308
Technical Report

NREL/TP-5D00-75290

October 2021

National Renewable Energy Laboratory 15013 Denver West Parkway Golden, CO 80401

303-275-3000 • www.nrel.gov 


\section{NOTICE}

This work was authored by the National Renewable Energy Laboratory, operated by Alliance for Sustainable Energy, LLC, for the U.S. Department of Energy (DOE) under Contract No. DE-AC36-08GO28308. This material is based upon work supported by the U.S. Department of Energy's Office of Energy Efficiency and Renewable Energy (EERE) under the Solar Energy Technologies Office Award Number 34808.

This report is available at no cost from the National Renewable Energy Laboratory (NREL) at www.nrel.gov/publications.

U.S. Department of Energy (DOE) reports produced after 1991 and a growing number of pre-1991 documents are available free via www.OSTI.gov.

Cover Photos by Dennis Schroeder: (clockwise, left to right) NREL 51934, NREL 45897, NREL 42160, NREL 45891, NREL 48097, NREL 46526.

NREL prints on paper that contains recycled content. 


\section{Preface}

The intent of this document is to support the local Authorities Governing Interconnection Requirements (AGIRs ${ }^{1}$ ) in adopting the most current requirements for interconnecting distributed energy resources (DERs) to the electric distribution system, as specified in the Institute of Electrical and Electronics Engineers Standard for Interconnection and Interoperability of Distributed Energy Resources with Associated Electric Power Systems Interfaces (IEEE Std 1547-2018).

To create interconnection rules that successfully address policy goals, market trends, and technical requirements, electric service regulators need to be well informed of DER integration considerations. Interconnection processes and technical issues often overlap; the two are not easily segregated, and they are often considered and evaluated concurrently within the context of interconnection rulemaking. Accordingly, this document addresses both the technical issues and related process considerations.

A lack of uniform and transparent procedures for addressing interconnection rule ${ }^{2}$ changes can result in implementation issues or inefficiencies, such as unclear, lengthy, and complicated interconnection rules that can increase distributed generation "soft costs" (i.e., non-hardware costs). Additionally, misconstructed interconnection rules are at risk of becoming mired in stakeholder conflicts.

This guide addresses the concerns of electric service regulators from both the process and technical standpoints by presenting a structured, step-by-step approach to developing and updating existing interconnection rules.

In this document, the process of developing and updating interconnection rules is subdivided into three steps: (1) determining the context (stakeholders and major drivers); (2) developing the rule, including updating technical requirements; and (3) maintaining and revising the rule over time.

Some key considerations for the AGIR include the following:

- Internal motivations for updating the rule. Has the AGIR sufficiently identified internal motivations for updating the interconnection rule and desired goal (outcome)?

- Stakeholder identification. Has the AGIR identified all of the stakeholders relevant to the effort?

\footnotetext{
${ }^{1}$ IEEE Std 1547-2018 defines the AGIR as a "cognizant and responsible entity that defines, codifies, communicates, administers, and enforces the policies and procedures for allowing electrical interconnection of DER to the area EPS. This could be a regulatory agency, public utility commission, municipality, cooperative board of directors, etc. The degree of AGIR involvement will vary in scope of application and level of enforcement across jurisdictional boundaries. This authority might be delegated by the cognizant and responsible entity to the area EPS operator or BPS operator" (IEEE 2018).

${ }^{2}$ Note that the word standard could be used to refer to both formal technical standards, such as IEEE Std 1547, and interconnection requirements as specified by local authorities. This document uses the term interconnection rule when referring to distribution grid interconnection requirements created by local authorities and the term standard when referring to standards published by a standards development body such as the IEEE.
} 
- Procedural timeline. Has the AGIR allotted sufficient time for stakeholder discussion and resolution of issues?

- Technical requirements. Has the AGIR allowed for the use of DER capabilities (even if they are to be used in the future)?

This work complements the existing knowledge and publications from various entities on recommendations for updating interconnection procedures.

Note that the narrative presented in this document reflects the authors' interpretations, which in some instances might differ from one user to another; therefore, this work is intended to supplement the existing and growing knowledge across the U.S. electric sector on DER interconnections and the use and application of IEEE Std 1547-2018.

This document supplements a series of publicly available resources available at the following: https://www.nrel.gov/grid/ieee-standard-1547/. 


\section{Acknowledgments}

The authors are grateful for the contributions, guidance, and support from members of this project's technical education committee: Jason Allnutt, Sara Baldwin, Jens C. Boemer, Maury Galbraith, Robert Harris, Brian Lydic, Richard McAllister, John Shenot, Ravi Subramaniam, and Kiera Zitelman; and, from our U.S. Department of Energy (DOE) leadership on the committee, Michele Boyd, Joe Palladino, and Robert Reedy.

The authors express their sincerest appreciation to Michelle Rosier and Julie Baldwin for their written contributions to this report.

The authors thank Jose Cordova, Nadav Enbar, Sky Stanfield, Sherry Stout, and Rebecca Glaser for their review and valuable comments. The authors are also grateful to DOE Office of Energy Efficiency and Renewable Energy (EERE) Solar Energy Technologies Office (SETO) Strategic Analysis and Institutional Support Program Manager Michele Boyd, to Robert Reedy and Jeremiah Miller; and to Systems Integration Program Manager Guohui Yuan for guidance and support.

This material is based on work supported by DOE EERE under the SETO Award Number 34808 . 


\section{List of Acronyms}

AGIR

BPS

DER

DSIRE

EPS

ERCOT

FERC

HECO

IEEE

IREC

IRENA

KPI

MISO

MPSC

MW

NARUC

NEC

NEMA

NERC

NFPA

NREL

PV

RPS

RRC

SECC

SGIA

SGIP

VAR
Authority Governing Interconnection Requirements

bulk power system

distributed energy resource

Database of State Incentives for Renewables \& Efficiency

electric power system

Electric Reliability Council of Texas

Federal Energy Regulatory Commission

Hawaiian Electric Companies

Institute of Electrical and Electronic Engineers

Interstate Renewable Energy Council

International Renewable Energy Agency

key performance indicator

Midcontinent Independent System Operator

Michigan Public Service Commission

megawatt

National Association of Regulatory Utility Commissioners

National Electrical Code

National Electrical Manufacturers Association

North American Electric Reliability Corporation

National Fire Protection Agency

National Renewable Energy Laboratory

photovoltaic

renewable portfolio standard

regional reliability coordinator

Smart Energy Consumer Collaborative

Small Generator Interconnection Agreement

Small Generator Interconnection Procedures

volt ampere reactive 


\section{Table of Contents}

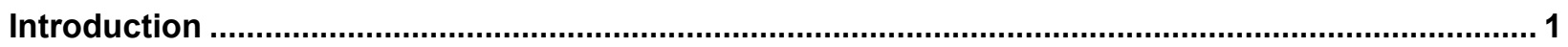

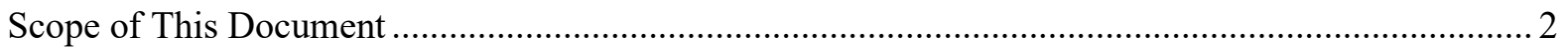

1 Step 1: Determining the Context-Stakeholders and Major Drivers .......................................... 4

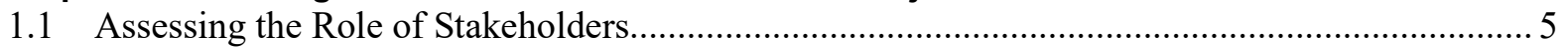

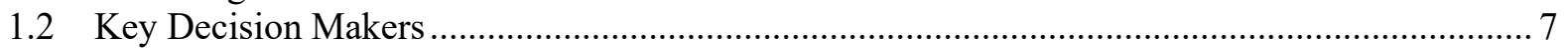

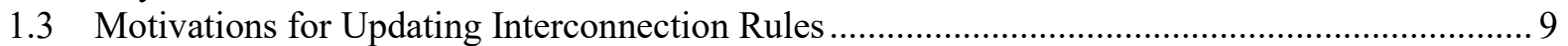

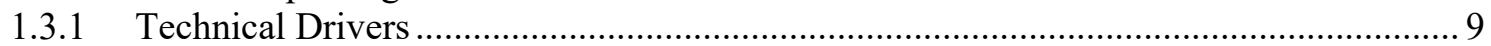

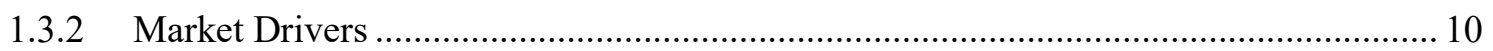

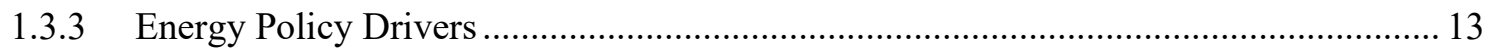

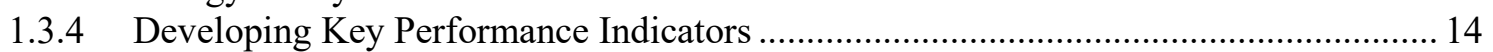

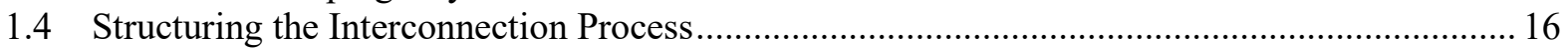

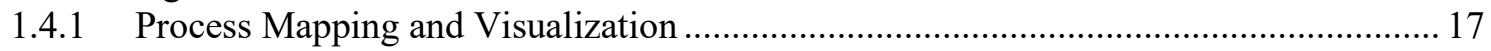

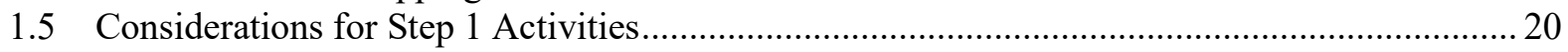

2 Step 2: Developing the Distributed Energy Resource Interconnection Rule .............................24

2.1 Broader Context for Distributed Energy Resource Interconnection Rules ................................ 24

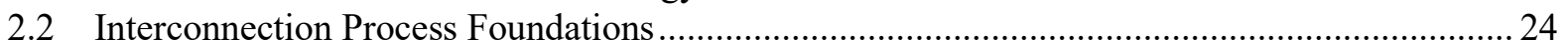

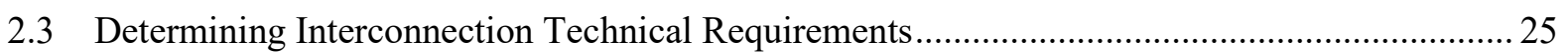

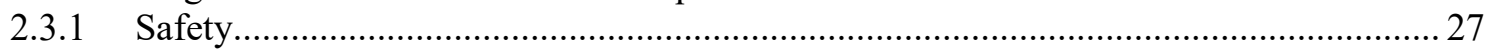

2.3.2 Reliable Operation and Good-Quality Electric Power ................................................. 28

2.3.3 Protection of Electric Power System and Customer Equipment .................................... 29

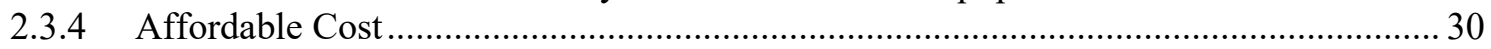

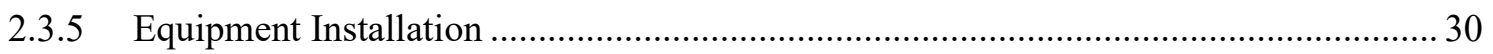

2.4 Considerations for Utilization of New Capabilities Enabled by IEEE Std 1547-2018 ............... 30

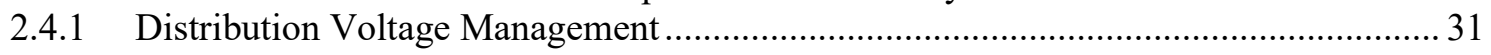

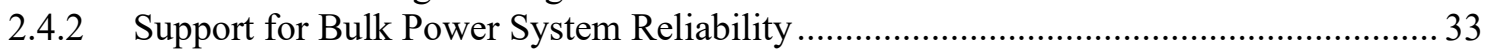

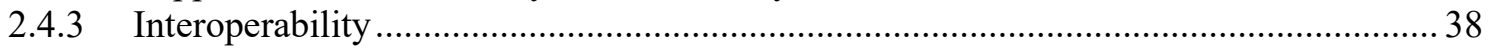

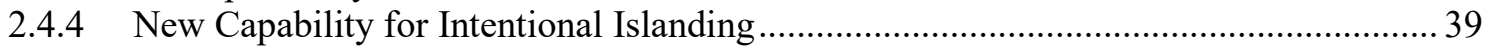

3 Step 3: Maintaining and Revising the Interconnection Rule..................................................... 41

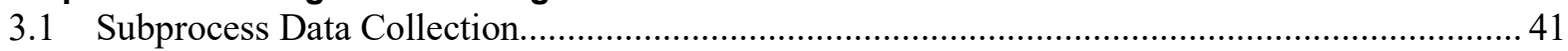

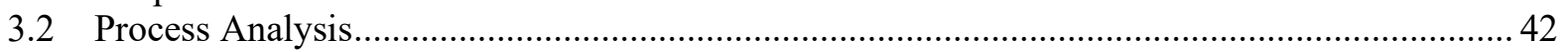

3.3 Requirements for Distributed Energy Resource System Modifications and Maintenance ......... 42

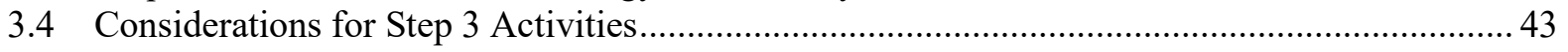

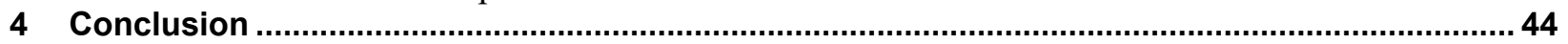

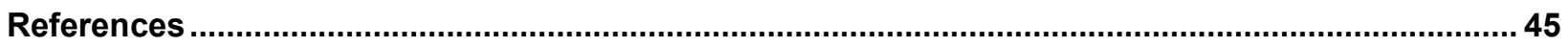

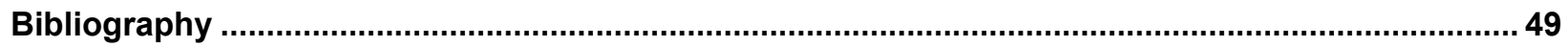




\section{List of Figures}

Figure 1. Status of DER interconnection rules in the United States .................................................... 2

Figure 2. Subdivision of interconnection rulemaking process ........................................................ 3

Figure 3. U.S. Energy Information Administration projection: Increasing distributed generation.............. 4

Figure 4. Convener and participating stakeholders in the interconnection rulemaking process .................. 6

Figure 5. Decision framework for interconnection technical requirements ............................................ 9

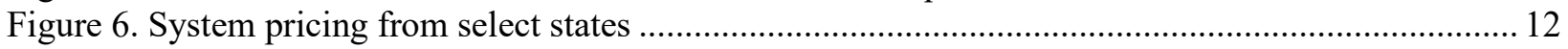

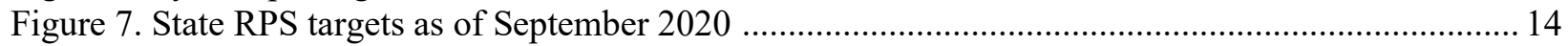

Figure 8. Interconnection process engineering life cycle. (Activities in green are discussed in Step 3.) .. 17

Figure 9. Example audit diagram of interconnection phases .............................................................. 19

Figure 10. Growth of distributed PV in Honolulu, Hawaii................................................................... 22

Figure 11. Cumulative capacity of residential and commercial PV in HECO service area......................22

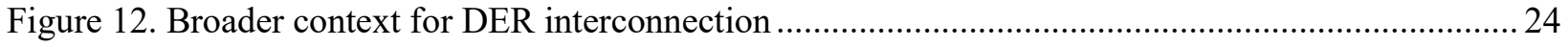

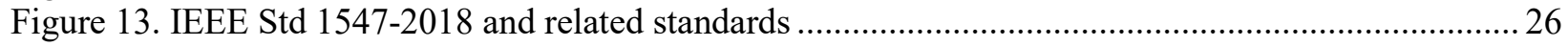

Figure 14. One-line diagram of an example distribution feeder, adapted from Beaty and Fink (2007) ..... 27

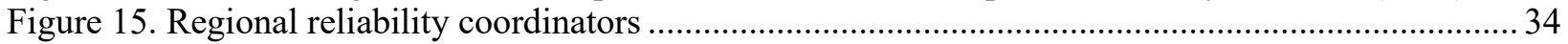

Figure 16. Illustrative comparison of voltage ride-through capabilities for category I, II, and III DERs... 37

Figure 17. Illustrative figure showing frequency ride-through requirements for all DERs ....................... 37

Figure 18. Scope of IEEE Std 1547-2018 power and communications .................................................... 38

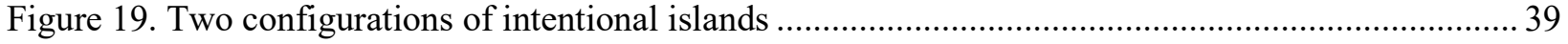

Figure 20. Feedback and renewal of interconnection rulemaking process ............................................ 43

\section{List of Tables}

Table 1. Key Performance Measurement Check............................................................................. 16

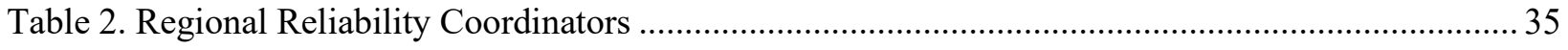

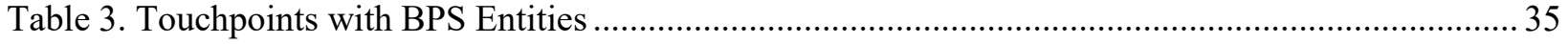




\section{Introduction}

Interconnection rules ${ }^{3}$ specify the procedures and technical requirements that determine how a distributed energy system can be interconnected to the electric grid. At the state level, public service commissions ${ }^{4}$ typically establish interconnection rules that apply when interconnecting distributed energy resources (DERs) to distribution systems served by investor-owned utilities. Municipal utilities and cooperative utilities also implement interconnection procedures and standards, though they are not typically under the jurisdiction of public service commissions. In the United States, these interconnection standards vary from one state to another; however, jurisdictions often rely on national interconnection standards, such as the Institute of Electrical and Electronics Engineers Standard for Interconnection and Interoperability of Distributed Energy Resources with Associated Electric Power Systems Interfaces (IEEE Std 1547-2018 ${ }^{5}$ ), as a basis. Some jurisdictions adapt the Federal Energy Regulatory Commission (FERC) rules and processes - the Small Generator Interconnection Procedures (SGIP) and the Small Generator Interconnection Agreement (SGIA), which were developed for projects subject to FERC's jurisdiction and apply to DER installations up to 20 megawatts (MW) in size. ${ }^{6}$ In addition, specific utilities might have their own additional procedures for interconnecting DERs to their network. Figure 1 provides an overview of the states that have implemented DER interconnection rules within the United States.

\footnotetext{
${ }^{3}$ Note that the word standard could be used to refer to both formal technical standards, such as IEEE Std 1547, and interconnection requirements as specified by local authorities. This document uses the term interconnection rule when referring to interconnection requirements created by local authorities and the term standard when referring to standards published by a standards development body such as the IEEE.

${ }^{4}$ In the United States, all 50 states have an entity that regulates utilities; however, these bodies might be referred to as the utility regulatory commission, public utilities commission, or public service commission. For simplicity, this guide uses public service commission to refer to these entities.

${ }^{5}$ The IEEE 1547 family of standards is the critical foundation for distributed generation interconnection to the electric utility distribution grid. The standard establishes criteria and requirements for how DERs can interact with the local electric power systems. The full family of standards provides requirements relevant to the performance, operation, testing, safety considerations, monitoring, and maintenance of the interconnected distributed generation system.

${ }^{6}$ For example, see "FERC Jurisdiction over Distribution Interconnections and Required PJM Involvement," available at https://www.pjm.com/-/media/committees-groups/task-forces/nemstf/20120206/20120206jurisdictional-chart.ashx.
} 


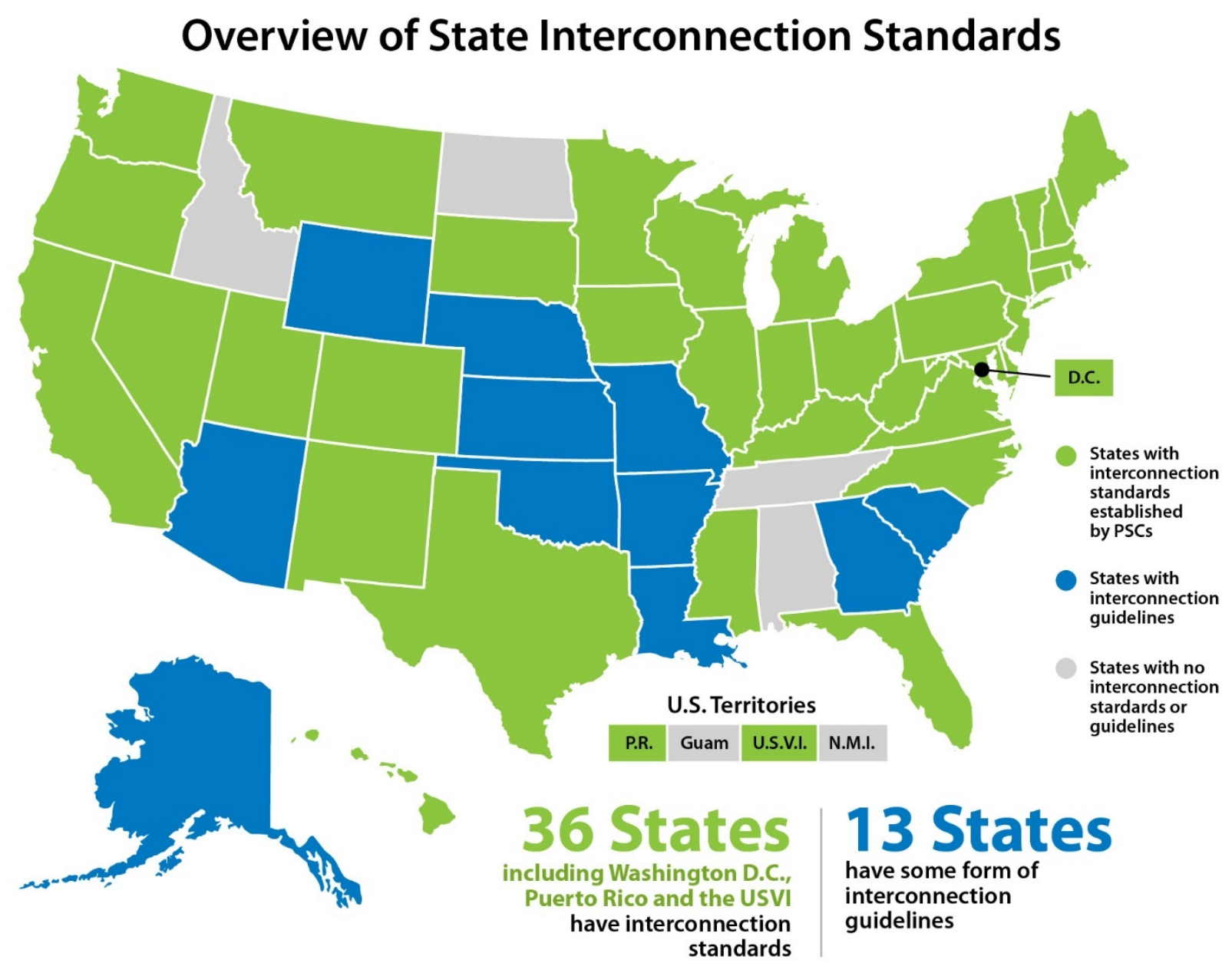

Source: Based on information from the Database of State Incentives for Renewables \& Efficiency, North Carolina Clean Energy Technology Center

Figure 1. Status of DER interconnection rules in the United States

\section{Scope of This Document}

In addition to the Authorities Governing Interconnection Requirements (AGIRs), the audience for this guide includes utilities - including investor-owned utilities, municipal utilities, and cooperatives — as well as other interconnection stakeholders.

This guide presents a structured, step-by-step approach to help AGIRs and stakeholders develop and update existing interconnection rules and incorporate IEEE Std 1547-2018 from both the process and technical standpoints. The process of developing and updating interconnection rules has been subdivided into three steps, as shown in Figure 2. 


\section{INTERCONNECTION PROCEDURE RULEMAKING PROCESS}

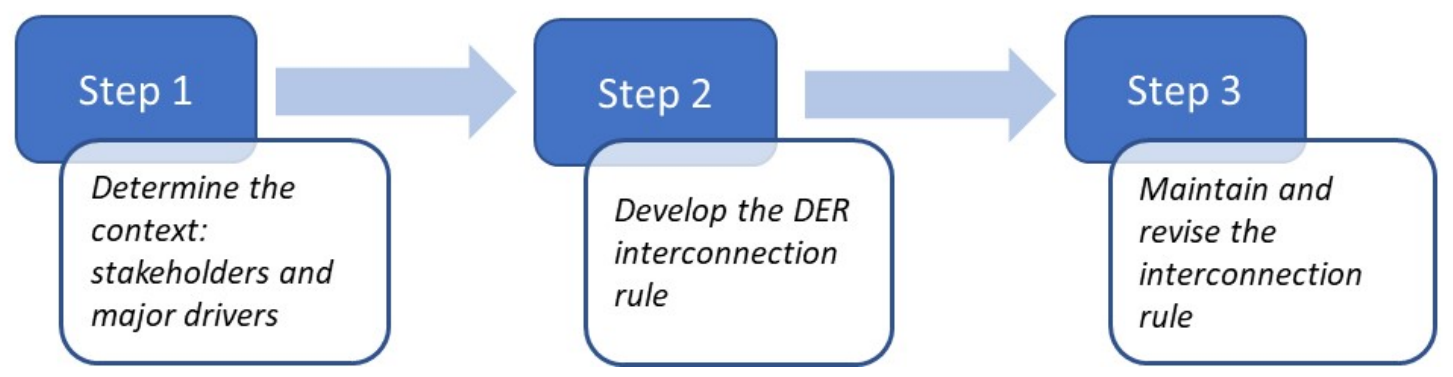

Figure 2. Subdivision of interconnection rulemaking process

All steps are discussed in detail in the following sections. This guide also addresses and incorporates prevailing problematic issues and queries identified by electric utility regulators to assist them in clearly articulating DER interconnection rules that can enable DER adoption and make interconnection processes more efficient. 


\section{Step 1: Determining the Context-Stakeholders and Major Drivers}

The rapid deployment of DERs has been driven in part by clean energy goals at the state and local levels. Additional policy and technical drivers, coupled with strong consumer demand for renewable energy resources, has fueled the adoption of DERs. Analysis by the U.S. Energy Information Administration projects that DER adoption will continue to increase in the coming decades, as shown in Figure 3. Accordingly, demand for interconnections will also likely increase. Future interactions will include not only the traditional utility and consumer/customer but also third parties, such as DER aggregators or other types of customers supplying grid services.

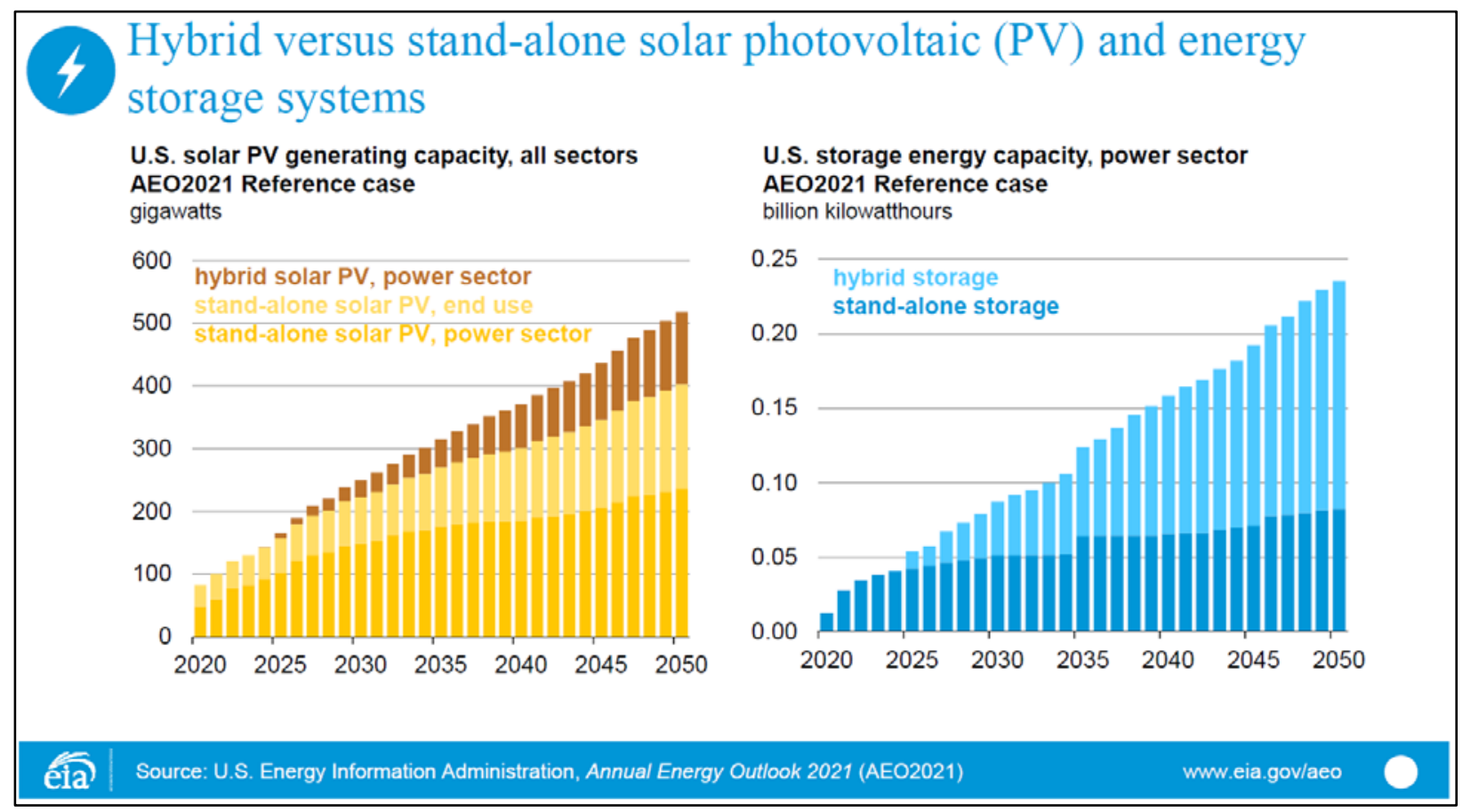

Source: U.S. Energy Information Administration AEO2021

Figure 3. U.S. Energy Information Administration projection: Increasing distributed generation

Interconnection rules facilitate the development of transparent and efficient processes to ensure the safe and widespread deployment of DERs. The efficiency of interconnection rules is driven by their ability to meet the needs and requirements of the stakeholders that are associated with the process at the operations level.

Two important activities constitute Step 1 of the interconnection rulemaking process. The first activity is determining the socioeconomic and technical contexts for updating the interconnection rule and identifying the goals and expectations of stakeholders that affect and/or are affected by the interconnection rulemaking process. (See sections 1.1, 1.2, and 1.3 of this guide.)

Updating interconnection processes and technical requirements depends on many factors and should be determined for each jurisdiction based on relevant conditions, such as current and 
projected DER penetration levels, distribution system characteristics, organizational structure of utilities, and stakeholder objectives.

By first developing an understanding of the viewpoints, expectations, and needs of all stakeholders and by gaining a clear understanding of the drivers for updating the interconnection rule, a shared purpose is established. This shared goal can then result in a workable interconnection rule that matches the goals and expectations of the various stakeholders.

The second activity in Step 1 is structuring the interconnection process by applying tools and techniques for monitoring indicators, process visualization, and analysis. The application of these methods can help the AGIR improve efficiency and reduce costs for the interconnection process. (See Section 1.4 of this guide.)

An essential part of the second activity is a review of the stakeholder drivers of both the interconnection process and the technical changes. Conducting an initial assessment of stakeholder goals along with their primary drivers then converting them into stakeholder requirements can be useful in the development of key performance indicators (KPIs) and critical metrics for evaluating the efficiency of the proposed interconnection rules such that stakeholder goals are explicitly addressed. (This process is discussed in Section 1.3.3 of this guide.)

\subsection{Assessing the Role of Stakeholders}

Through stakeholder collaboration, interest groups and entities with similar or different objectives can mutually identify shared goals that go beyond individual interests and establish a vision of what is achievable. Leveraging explicit (or implicit) goals and process validation metrics to establish a common and shared purpose for the stakeholders can provide a strong framework for addressing complex problems in existing DER interconnection processes that otherwise isolated efforts cannot solve. In addition to promoting an inclusive and nonhierarchical participatory environment, this approach encourages a joint sense of responsibility among stakeholders to ensure the successful enforcement of interconnection rules.

Different stakeholders are involved to varying degrees in the interconnection decision-making process. It is critical to understand the impact that these stakeholders can have on the interconnection process and their relevance in driving the process. The degree to which a stakeholder might be involved in the collaboration process could vary from a central decisionmaking role to a consultative role. Stakeholders such as utilities, DER developers, and customer advocates typically represent entities directly affected by interconnection rules and thus are central to interconnection rulemaking, development, and enforcement.

Additionally, interconnection stakeholders can be classified into two categories: conveners of the interconnection working group and participating stakeholders. In most cases, the state public service commission is the convener of the interconnection working group. Figure 4 shows an overview of the major organizations and entities involved in the DER interconnection rulemaking process. 


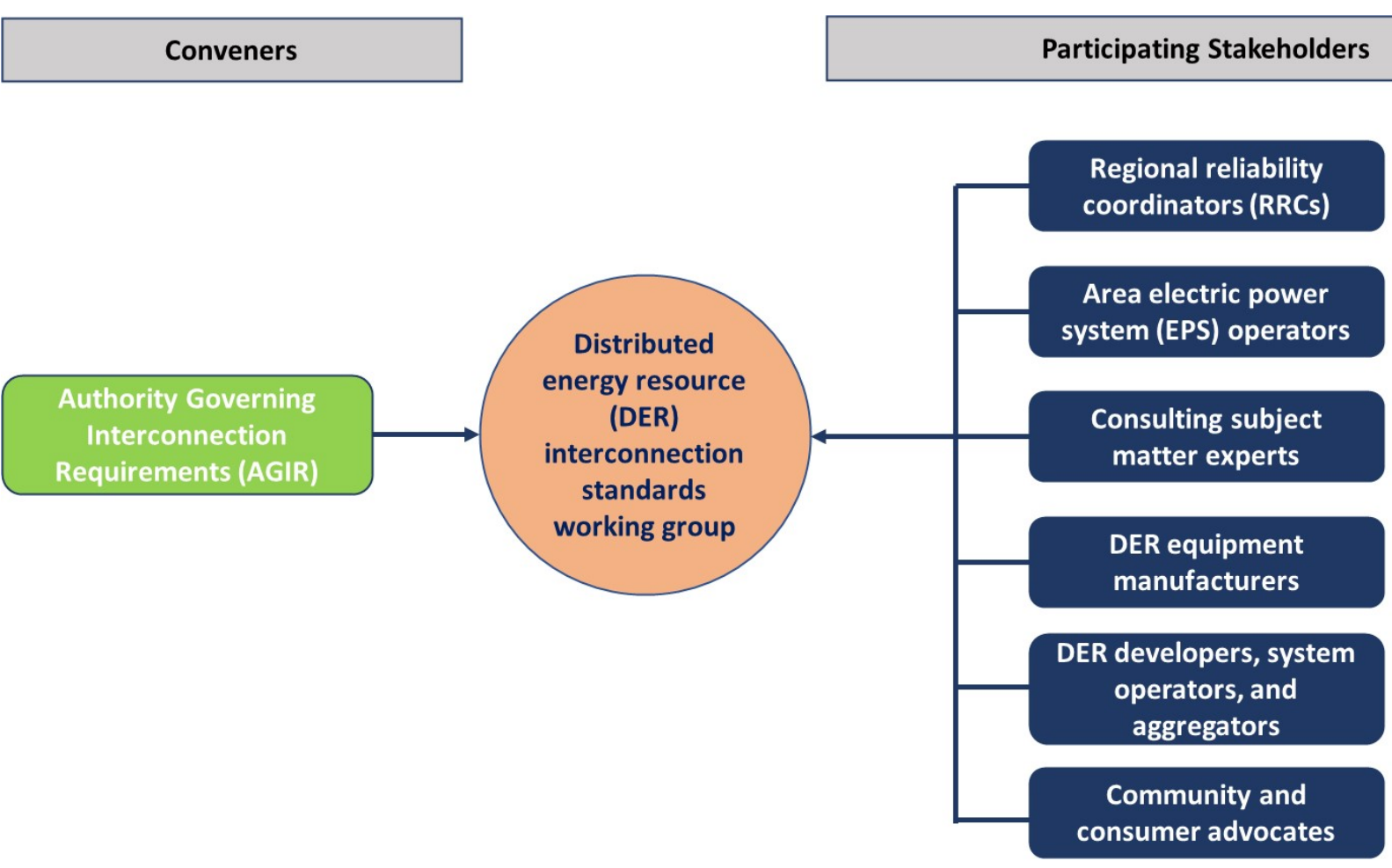

Figure 4. Convener and participating stakeholders in the interconnection rulemaking process

Facilitators or conveners of the collaboration process must strategically plan both the scope and duration of stakeholder involvement and the process's primary objectives. A shared purpose can be a powerful driver of collaborative performance by providing both motivation and direction for members' joint problem-solving efforts. Failure to involve all stakeholders in collaboration efforts can lead to subsequent process implementation issues and technical or political difficulties in achieving DER interconnection objectives.

Transforming the rulemaking process into an open and participatory process for stakeholders from diverse backgrounds and knowledge bases allows for the formulation of shared goals and objectives for the interconnection working group. The convenor must act as a strong facilitator who both enforces professional courtesy and open dialogue and informally applies the tenets of "Roberts Rules of Order" (Roberts 1998). This approach also mitigates the risks associated with the introduction of bias in the rule's objectives, since bias is often induced by domination of the strongest or best-resourced interest groups.

Prior to updating the interconnection rule, it is important and helpful for the stakeholders to establish common definitions, nomenclature, and terms for key concepts to help facilitate further collaborative work. People are often driven by the clear definition of goals and an overarching purpose. When individuals (and the companies they represent) see how collaboration benefits a larger cause, they can be more committed and engaged. Negotiating a common and shared purpose is a fundamental building block of successful collaboration (Nayar 2014). Meaningful collaborative participation might be hampered without this foundation of common understanding and how terms and concepts will be used in context with each other. Taking the time to clarify definitions and terms at this early stage — before reaching conclusions or attempting action_-will help prevent unnecessary misunderstandings and delays in the work. 
At any time, different stakeholders can be motivated by one or more overarching and interrelated objectives. It is critical to involve entities and stakeholders affected by the implementation of the rule at appropriate stages of the interconnection rulemaking process. For example, implementing certain DER capabilities, such as voltage regulation and interoperability, could have implications beyond the strict scope of IEEE Std 1547-2018. These implications could include grid modernization policy goals and strategies, market strategies for enabling aggregated grid services from DERs, the integration of DERs into DER management systems or advanced distribution management systems, communications with aggregators and customer-sited devices, and cybersecurity frameworks and postures. Because of these potential implications, the standard is structured so that AGIRs have input on decisions to enable and implement these technical capabilities by the area electric power system (EPS) operator.

\subsection{Key Decision Makers}

The National Renewable Energy Laboratory's (NREL's) Clause-by-Clause Summary of Requirements in IEEE Standard 1547-2018 (Narang et al. 2020) provides the next order of detail beyond this overall framework, identifying key stakeholders and their expected level of involvement in each key decision related to the implementation of the standard. The three decision-maker groups include the AGIR, the regional reliability coordinator (RRC), and the area EPS operator.

\section{Authority Governing Interconnection Requirements (AGIR). The AGIR is the} entity that has the authority to set the interconnection requirements used in a local territory. The AGIR must define use cases, select inverter categories for functionality (performance categories), set timelines, and update other relevant codes or rules. The standard makes clear that the degree of AGIR involvement will "vary in scope of application and level of enforcement across jurisdictional boundaries..." (IEEE 2018). Informative footnote 12 in the standard adds that "it remains in the responsibility of an AGIR to quantify impactful DER penetration

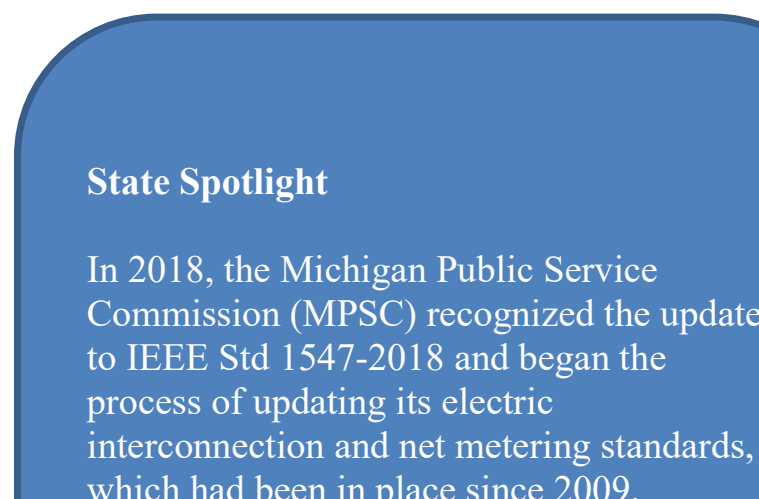
which had been in place since 2009 .

An initial draft was provided to the groups for comment in August 2019, due by September 2019. During that period, MPSC staff met individually with stakeholders upon request. In February 2020, an updated second draft was provided to the working groups, with comments due by May 2020. MPSC staff are reviewing the comments and reaching out to commenters for clarification when needed. A final draft is not yet available. levels" (IEEE 2018). This is because mitigating potential adverse contributions (i.e., "impacts") that DERs might have on frequency or voltage quality can require balancing local and bulk system perspectives. 
In general, the AGIR is the state public service commission, but the standard lists several other entities that might hold this responsibility or might share it. For most distributed rural cooperatives, at least some portion of this responsibility will likely rest with the cooperative's governing board, but the AGIR's responsibility might be shared among more than one organization. For example, requirements for certain functions with particular impacts on bulk power system (BPS) stability might be set by a generation and transmission provider or by an independent system operator, whereas local requirements could be set by the cooperative's governing board (Ropp 2019). (Note that some cooperatives are regulated by a public service commission.)

The role of the AGIR at community-owned electric utilities (i.e., municipal electric companies) might not be as clear-cut, however. Municipal electric utilities are typically governed by the city council or a board of directors and operate under one of the following models (Cruz, Berg, and Marques 2011):

- Operate as city departments (e.g., Los Angeles Department of Water and Power)

- Report to city council (e.g., Colorado Springs, Colorado)

- Operate as an independent city agency (e.g., Knoxville, Tennessee)

- City-owned corporation

- Municipal utility district (e.g., Sacramento Municipal Utility District)

- Joint powers agency

Regional reliability coordinator (RRC). At the transmission and bulk power levels, the RRC is the entity that maintains the real-time operating reliability of the BPS within their reliability coordinator area (IEEE 2018). RRCs have "the operating tools, processes and procedures, including the authority to prevent or mitigate emergency operating situations in both next-day analysis and real-time operations" (NERC 2018). In areas that have high renewable targets that could include large shares of inverter-based resources and/or large amounts of distributed generation, RRCs across the mainland United States are paying increasing attention to these resources in planning studies. Information on this new stakeholder can be found in this guide in Section 2.4.2, Support for Bulk Power System Reliability.

Area electric power system (area EPS) operator. In an interconnection, certain technical requirements are designed, very specifically, to meet the needs or constraints of a particular area EPS operator. These constraints could be because of the area EPS electrical configuration; area EPS operator distribution operation practices; decisions by the area operator on electrical safety, power quality, and protection coordination; specific requirements for testing and certification; requirements for voltage regulation; and requirements for communications or other interoperability or supervisory control and data acquisition system integration requirements. In IEEE Std 1547-2018, these types of technical requirements are in large part at the discretion of the area EPS operator because they directly affect the safety and operation of the distribution system.

Figure 5 provides the broader decision framework for interconnection technical requirements. Important DER capabilities that are included in IEEE Std 1547-2018 align with the technical requirements of three key stakeholders. Yet, as discussed, some grid modernization requirements and utilization of these capabilities, though introduced in the revised IEEE 1547 standard (IEEE 
Std 1547-2018), are beyond the standard's current intended scope. Shading is used in the figure to indicate the direct or primary responsibility for decisions related to the various technical requirements. Bidirectional arrows, connecting the three key stakeholders, represent the collaboration involved in the adoption and utilization of these important DER capabilities. The dashed arrows (pointing to "Interoperability" and "Support for bulk system") highlight important new capabilities introduced in this version of the standard. In the figure, the connection from the area EPS operator to the capabilities listed on the right represents the implementation of the interconnection rule and technical requirements in an agreement between the area EPS operator and the DER operator.

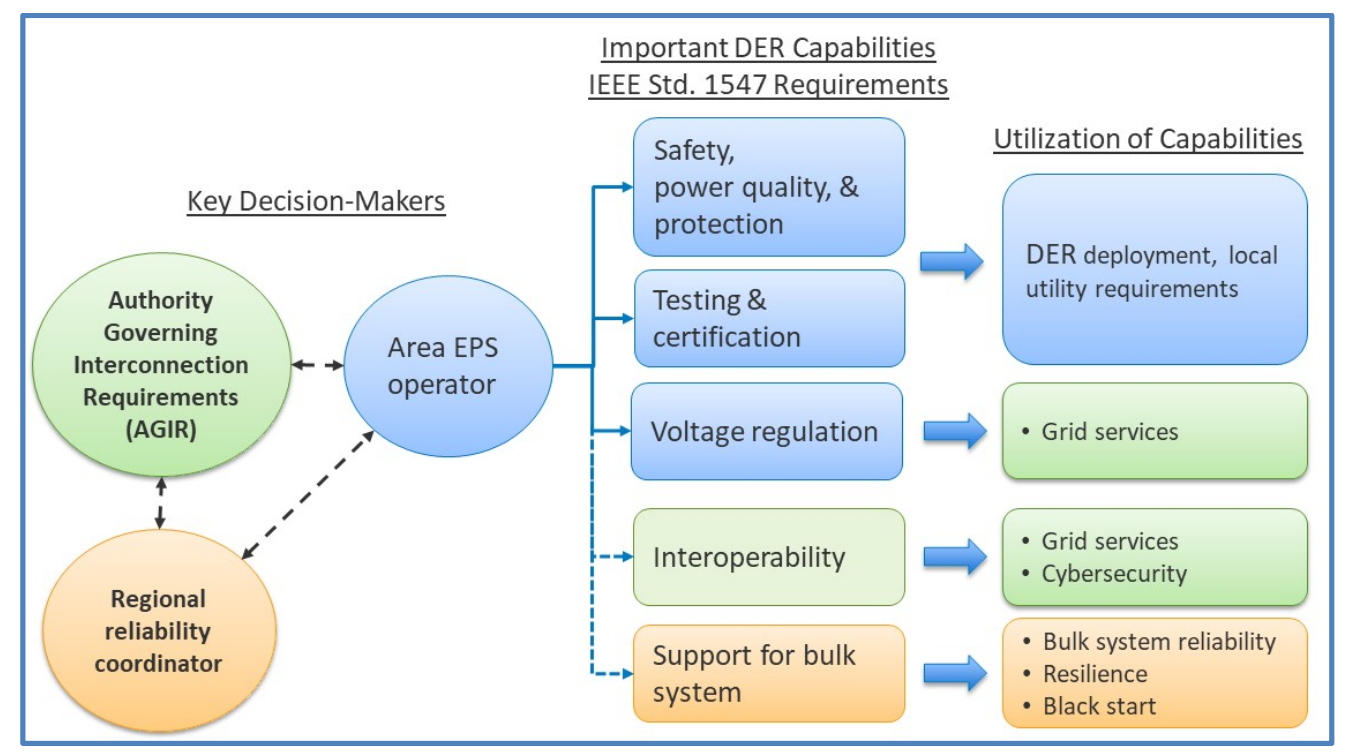

Figure 5. Decision framework for interconnection technical requirements

\subsection{Motivations for Updating Interconnection Rules}

The major drivers of DER adoption and interconnection process revisions can be broadly categorized into technical drivers, market drivers, and energy policy drivers.

Different stakeholders might be motivated by one or more of these drivers at a given time. By making stakeholders an integral part of the interconnection rulemaking considerations, AGIRs can ultimately develop performance metrics for interconnection process validation during the rulemaking and for interconnection process maintenance after the rulemaking is complete.

\subsubsection{Technical Drivers}

Technical drivers motivating changes to interconnection rules could include the following:

Improvements to DER hosting capacity. As DER adoption has increased across the United States, increasing the hosting capacity of local distribution circuits has become an important goal. Guidance from local jurisdictions on hosting capacity procedures, reports, or maps could be codified in interconnection rules.

Improvements to DER generation and status. Better information on DER generation production and status could help improve not only real-time distribution grid operation but also 
distribution planning models. Additionally, at a high level of deployment, DERs will affect the BPS. These types of considerations necessitate dialog among local AGIRs, BPS operators, and RRCs. Field experience can inform how these considerations are codified in interconnection rules.

\section{Updates to external technical standards or best practices. IEEE Std 1547-2018} contains many updates that enable advanced DER capabilities, such as voltage regulation and ride-through. Utilization of these new capabilities can be a strong motivation to update interconnection rules because many local jurisdictions are still operating under IEEE Std 1547-2003, which specifically prohibited many DER capabilities that are now recognized as important and even critical for continued increases in DER deployment.

\section{Considerations for DER impacts on BPS} reliability. DER deployment at a scale large enough to impact the BPS is currently evident in only a handful of states; however, planning for DER impacts to BPS reliability is actively occurring at a number of independent system operators, including the Midcontinent Independent System Operator (MISO), ISO New England, the Electric Reliability Council of Texas (ERCOT), and PJM. In addition, the North American Electric Reliability Corporation (NERC) has sponsored several working groups to research the potential impacts and to begin dialog for coordination with local jurisdictions. ${ }^{7}$

\subsubsection{Market Drivers}

As shown in Figure 3, DER adoption is projected to increase in the coming years. The historical growth and projected future increase are a result of a variety of trends, many of which are market driven. The most significant market driver has been the cost declines of DER technologies; however, customers are also motivated by improving resilience and climate change. These have contributed to increases in DER interconnection. In Michigan, for example, since 2019, two investor-owned utilities have experienced huge growth in their interconnection queues (from typically five interconnection applications per year to more than 1,000 MW of DER requests). Owing to the enhancement of interconnection standards (i.e., IEEE Std 1547-2018) and the trending increase in interconnection requests, the state commission included "updating interconnection rules" in its strategic plan (Michigan Public Service Commission 2018).

The major market drivers that can impact the interconnection process include the following:

\footnotetext{
${ }^{7}$ For a discussion on this topic, see NERC (2020), https://www.nerc.com/comm/PC_Reliability_Guidelines_DL/Guideline_IEEE_1547-2018_BPS_Perspectives.pdf.
} 
Declining costs of DER technologies. From an aggregation of partial 2018-2019 data from four states, the median reported PV system prices continued to decline in most capacity ranges. Figure 6 shows the 10-year system price (\$/W-DC) trend for four capacity ranges, based on data from California, Connecticut, Massachusetts, and New York.

Improved resilience. ${ }^{\mathbf{8}}$ Regulators and utilities are recognizing the role of DERs in addressing resilience.

Critical infrastructure - such as hospitals, police departments, fire stations, and other facilitiesprovide services that must operate during natural disasters that disable the electric grid. Large public buildings, such as schools, frequently serve as emergency shelters for prolonged recovery periods. Generally, dedicated diesel generators have been used to provide backup power for these types of sites. But as the cost of renewable generation and energy storage systems decrease, and as the capabilities of these systems improve, DERs are emerging as a viable alternative to traditional backup power generation. Yet, to permit the dual benefits of backup power and onsite generation that reduces utility bills and enables continued operation despite interruptions, DERs must be configured to provide these capabilities as an intentional island (microgrid), and "policies need to be explicitly designed to incentivize them" (Zitelman 2020). Traditionally, utilities and AGIRs have performed cost-benefit analyses for reliability investments but not for resilience investments (Murphy 2020).

Customer environmental consciousness. Consumers are making personal decisions broadly driven by environmental consciousness, and, similarly, they want their electricity from sustainable sources (Paaso, Svachula, and Bahramirad 2015). In consumer research conducted in 2019 by the Smart Energy Consumer Collaborative (SECC 2019), 44\% of consumers rated "helping the environment" as the next important benefit from DERs, after bill savings.

\footnotetext{
${ }^{8}$ The term resilience means the ability to prepare for and adapt to changing conditions and to withstand and recover rapidly from disruptions, according to the Presidential Policy Directive 21 (The White House 2013). The term can be conflated with reliability in utilities' grid modernization proposals. Although resilience and reliability are "closely related," a major distinction is that reliability is about preventing disruptions that are more common, local, and smaller, whereas resilience addresses high-impact events that can be longer term and widespread, according to NARUC (Rickerson, Gillis, and Bulkeley 2019). NREL expands on the Presidential Policy Directive 21 by defining resilience as 'a system's ability to anticipate, prepare for, and adapt to changing conditions and withstand, respond to, and recover rapidly from disruptions through sustainable, adaptable, and holistic planning and technical solutions" (Torres and Laws 2018).
} 


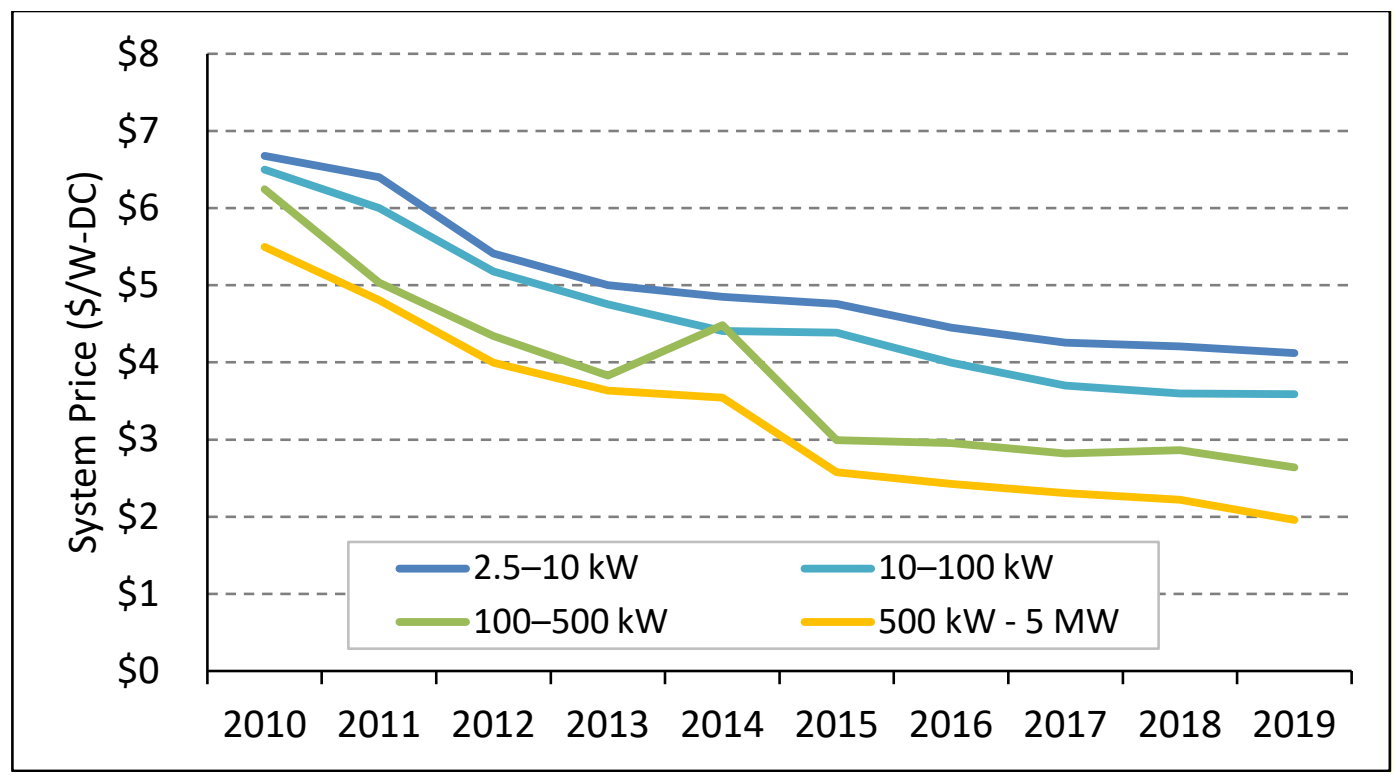

Data sources: California net energy metering database (10/31/19) (2015-2019); California Solar Initiative database (2010-2014); Connecticut Green Bank (09/30/19); Massachusetts Solar Renewable Energy Certificates program (12/06/19); New York State Energy Research and Development Authority (12/31/19)

Figure 6. System pricing from select states

Evolving ownership models. Third-party ownership models have had a significant impact on distributed energy deployment, especially in the residential sector. Although many variations of third-party ownership models exist, the fundamental operating mechanism involves a customer who hosts a distributed energy system (usually a PV system) on their premises but does not own the installed system; the system is financed, installed, and initially owned by a nonutility third party (the customer may obtain ownership of the system at the end of the lease term). Shared renewable systems are another way to structure and motivate renewable energy deployment. ${ }^{9}$ Economies of scale have helped community shared solar programs become a potential option for low-income households that do not have easy and affordable access to credit and cannot take advantage of federal tax credits for renewable energy. They also broaden participation opportunities for customers who cannot install a PV system on their residence-for example, because they have a shaded property, are renters, or have low income (Coughlin et al. 2012). As equity in energy policies and practices evolve, and as local, state, or federal incentives change, it is expected that interconnection rules will need to be updated to better include historically disadvantaged market segments (Cory, Canavan, and Koenig 2009). Under current mechanisms, less than half of community solar installations include low-income households (Gallucci 2019).

Equity in energy. Approximately 50 million households, or $44 \%$ of the U.S. total, fall into the low-income category - and these households face a disproportionately higher energy burden (DOE 2021). While only 15\% of solar PV adopters are from low-income households (Barbose et al. 2018), several states have developed policies to further include these individuals. For example, California has the Solar on Multifamily Affordable Housing program and the New Solar Homes Partnership. Massachusetts' Solar Carve-Out II program and the Solar

${ }^{9}$ Community shared solar allows customers to subscribe to or own shares in larger systems and receive utility bill credits based on the output of renewable energy systems that are not installed behind their individual meters. 
Massachusetts Renewable Target program provide tiered benefits based on income. New York offers the Affordable Solar Initiatives and Affordable Solar Predevelopment and Technical Assistance program. Additionally, California, Colorado, New York, and Oregon have incorporated low-income initiatives into their community solar policies (Sunter, Castellanos, and Kammen 2019).

\subsubsection{Energy Policy Drivers}

Energy policies can be a major reason to update interconnection rules. In the United States, energy policies can be developed and implemented at the federal, state, and local levels.

National legislation. National legislation can spur growth in distributed energy deployments, which can, in turn, necessitate interconnection rule updates. Examples are the Energy Policy Act of $2005^{10}$ and the Energy Independence and Security Act of 2007. ${ }^{11}$ Other federal policies and financial incentives - such as the production tax credit, the investment tax credit, and the Modified Accelerated Cost-Recovery System - are also designed to encourage the adoption of renewable energy systems. National policies can be complemented by state or local policies.

State policy. State objectives for the adoption of DERs and the encouragement of new technologies manifest through a variety of mechanisms, including renewable portfolio standards (RPS), voluntary renewable energy targets, public benefit funds for renewable energy, and rate design that encourages DERs. RPS policies differ widely by state, as shown in Figure 7. In most states, the RPS is expressed as an annual required minimum percentage of electricity sales to retail consumers from eligible resources.

\footnotetext{
10 The Energy Policy Act of 2005 aided renewable and distributed energy adoption by directing the Secretary of Energy to make available grants for developing renewable and distributed energy, and it provided funding for the research, development, and demonstration of distributed generation and storage technologies, strategies, and projects. (See Energy Policy Act of 2005, SEC. 126, SEC. 251, SEC. 901, https://www.ferc.gov/enforcement/enforce-res/EPAct2005.pdf.)

11 The Energy Independence and Security Act of 2007 provided funding for research and demonstrations of energy storage technologies, deployment, and integration of distributed generation, including renewable resources, and other technologies in support of grid modernization. It also created a program to provide a $20 \%$ reimbursement for qualifying investments, including customer or third-party- (nonutility-) owned and operated distributed generation. (See Energy Independence and Security Act of 2007, SEC 641, SEC 1301, (https://www.govinfo.gov/content/pkg/PLAW-110publ140/pdf/PLAW-110publ140.pdf.)
} 


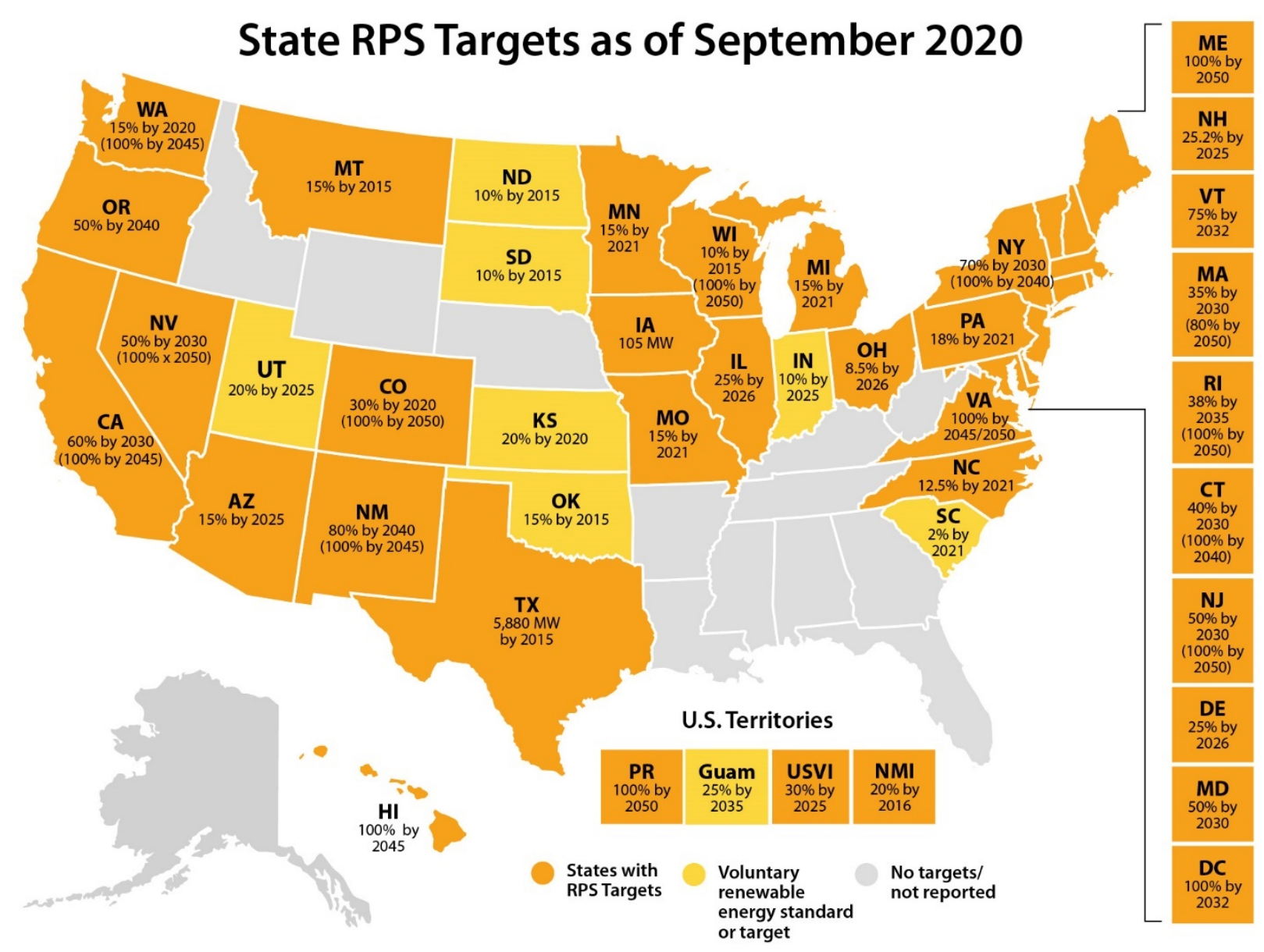

Figure 7. State RPS targets as of September 2020

Local policy, legislation, and decisions. Local energy policies can be made by city governments, cooperative boards, or municipal boards. Examples of local policies that can influence interconnection rules include setting goals for the deployment of renewable energy resources, including the integration of energy storage into the electric grid, and establishing tariffs for customers who generate electricity from DERs on their own premises (i.e., "behind the meter").

\subsubsection{Developing Key Performance Indicators}

W. Edwards Deming famously said, "What gets measured gets done." Developing a measurement plan that supports the goals and drivers developed in steps 1 and 2 in this document should not be overlooked. Although counting things might be a requirement because of policy or legislation, it is important that process- and subprocess-level data be collected to manage the maintenance of the interconnection rule.

The Interstate Renewable Energy Council (IREC) provides a useful list of data and reporting items related to individual projects (e.g., status, location) as well as overall interconnection process measures, such as "project demographics" (e.g., system size, fuel type; numbers of applications initiated, variously subjected to screens, and placed into commercial operation) (IREC 2019). These data are necessary but not sufficient for those charged with managing the 
health of the interconnection process, including making improvements. Also, these sorts of process measures do not address the stakeholder requirements and primary drivers.

Converting these strategic issues into KPIs can be very useful for evaluating the efficacy of the interconnection rule or procedure. KPIs can be tracked and compared to historical or expected values - both to describe interconnection rule performance and to identify instances where implementation deviates from expectations to prompt corrective action. KPIs combine data from multiple points to provide an overall context of implementation "health."

The steps for developing KPIs are outlined as follows (Sink 1989):

1. Collectively define the performance criteria of each strategic issue. Performance criteria might include effectiveness, efficiency, quality, productivity, cost, and timeliness (schedule). Think about each performance criteria as instruments on an operator's dashboard. Each strategic issue (i.e., stakeholder requirements and major drivers) might have different performance criteria, just as there are clusters of operator instruments for energy production, performance/quality, and communications.

2. As if specifying an operator's instrument, define the attributes and criteria of each relevant performance criteria. If stakeholders are unable to conceptually define these attributes, measurement will not be possible — and this might indicate these are not relevant or essential performance criteria.

3. For each performance criteria, stakeholders must link them to the scope-i.e., updating the interconnection process. That is, is each performance criteria within the scope of the interconnection rulemaking and its implementation? If stakeholders are unable to conceptually make this connection, measurement will not be possible — and this might indicate a disconnect or that more consideration is needed.

A tool like outlined in Table 1 is useful to validate the three KPI development steps. In the example depicted, for example, no performance criteria were identified for Major Driver \#2, and only effectiveness is relevant to Major Driver \#1. If these results are not acceptable to the stakeholders, the process can be revisited. 
Table 1. Key Performance Measurement Check

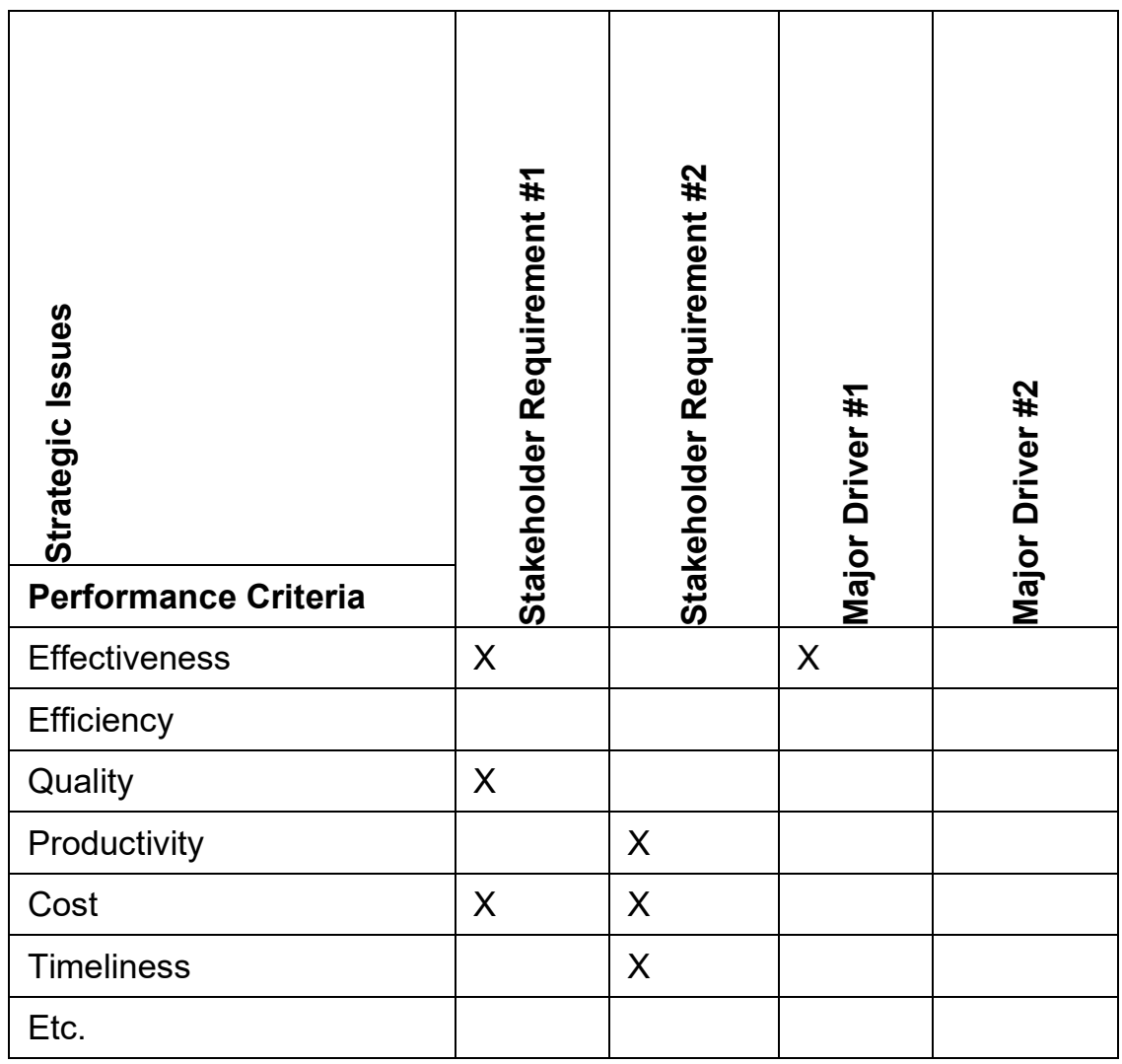

\subsection{Structuring the Interconnection Process}

Process engineering is a vital component of structuring DER interconnection rules. This method relies on incorporating tools and techniques for process visualization and analysis. The analysis of process effectiveness with respect to metrics and objectives identified as part of the Step 1 and Step 3 activities can enable the AGIR and utilities to identify critical bottlenecks responsible for reducing efficiency and inflating time and costs for the interconnection process. Process analysis includes the detailed investigation into process subactivities and the information exchange occurring among participating elements. Accordingly, it can help identify target areas for potential improvements, making it easier to carry out the reengineering of state or utility rules to address critical deficiencies in existing process workflows and to structure new rules. Figure 8 shows the overview of process engineering activities that can aid in structuring new and updated interconnection rules, and it can be carried out once the rules are enforced. 


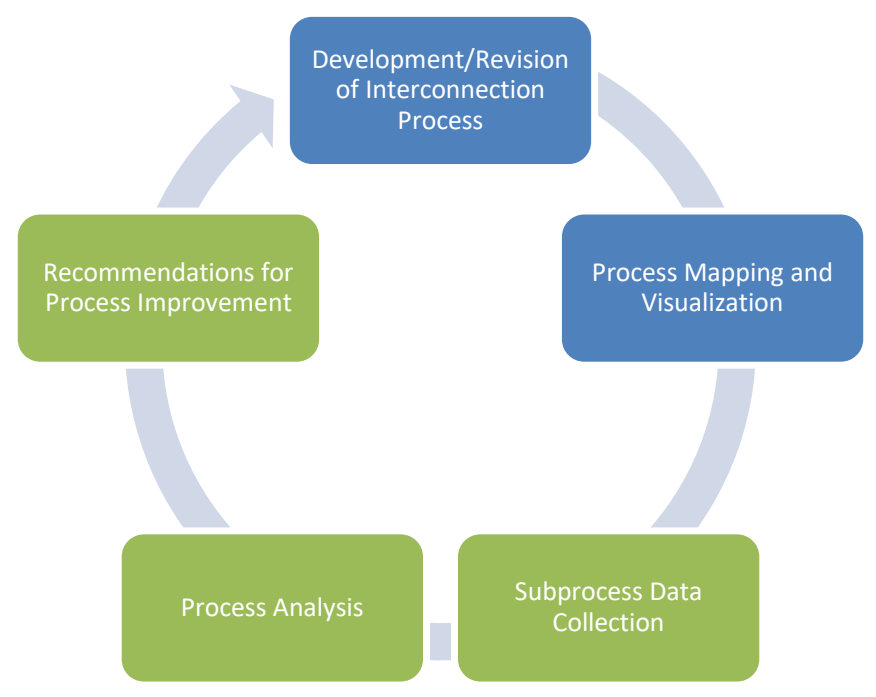

Figure 8. Interconnection process engineering life cycle. (Activities in green are discussed in Step 3.)

\subsubsection{Process Mapping and Visualization}

\section{Audit Diagrams}

Often, informative diagrams of interconnection processes and screens are included in the interconnection rule. The collaborative development of process diagrams from the interconnection rule can be helpful in implementing and validating the functional accuracy of existing processes. Process flowcharts provide a convenient way for stakeholders to visualize and examine the existing process workflow. Additionally, they help stakeholders understand the flow of information among participating entities and the time involved in information handoffs.

Interconnection processes vary from one state to another; however, there are a few functional similarities among all workflows. A preliminary analysis of DER interconnection processes reveals that most interconnection processes activities can be clustered into five phases:

- Phase 1: Project initiation/interconnection application

- Phase 2: Interconnection screening/study

- Phase 3: Construction

- Phase 4: Testing and inspection

- Phase 5: Interconnection and system energization.

The entire process can be subdivided into major phases to facilitate phase-wise analysis of activities ranging from project inception to termination, whereby the system interconnects with the grid at the identified point of common coupling. Additionally, a time estimate for each phase can be calculated for visualizing the expected time duration for the standard and the expedited interconnection procedures. Clustering activities into phases can help analysts determine the process time and cost involved for the area EPS operator and end consumers across each phase of the interconnection process.

An audit diagram technique is a powerful supplemental tool for categorizing processes in a structured format that can further aid the phase-by-phase analysis of the process. This technique 
provides a well-structured numbering schema to designate a number to each process step for easy reference. At every decision block, steps with a positive decision outflow are numbered in whole-number digits, whereas steps corresponding to a negative decision outflow are tracked through progressive levels of decimal digits. The audit diagram approach of numerical labeling as applied to the process flowchart diagram can be actively used to support performance management. This schema is particularly useful for performance managers and quality auditors in the identification and elimination of bottlenecks because it facilitates the identification of procedure steps that hold the largest in-process procedure queues (backlogs). An example is provided in Figure 9. 


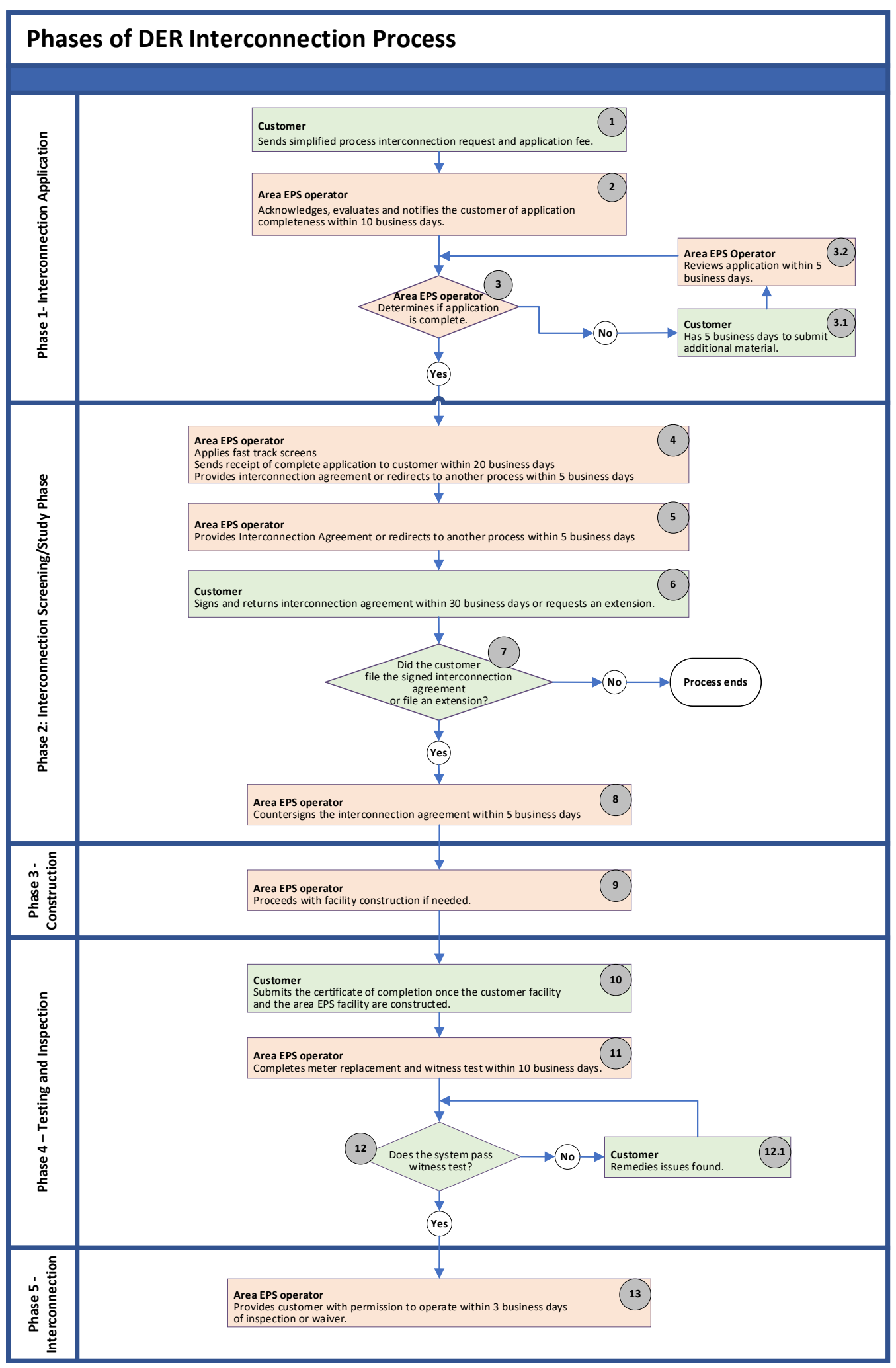

Figure 9. Example audit diagram of interconnection phases

\section{Process Mapping}


Process mapping is an additional technique used to visualize the interconnection process and to identify redundancies and inefficiencies. If there are several handoffs, either among various organizations or internal utility departments, it might be useful to extend functional flowcharts into a set of activity diagrams. Activity diagrams are a set of process mapping techniques used to distinguish responsibilities and handoffs among participating entities within a business process. Activity diagrams can be used in conjugation with audit diagrams developed as part of process analysis activities; however, it is important that the labeling (audit diagram) is consistently and accurately transferred to the activity diagram.

In contrast to the phase-by-phase clustering of process activities, activity diagrams cluster each process subtask based on the entity/organization responsible for undertaking the activity.

These diagrams can be invaluable to planning and monitoring the implementation of the interconnection rule. Analyzing timelines, work-in-process inventories (i.e., queues), and handoffs can reveal opportunities for improvement, including identifying process bottlenecks. Defining process boundaries at the point of exchange or handoff of responsibility can be clearly visualized through swim lanes or activity diagrams. These diagrams serve to clarify process ownership and responsibilities, duplication of efforts, and potentially narrow in on bottlenecks and process delays. Additionally, activity diagrams allow the process analyst to identify limited or no-value-added exchanges or duplications of effort, which are opportunities for process streamlining. Likewise, high-value but under-resourced tasks can be identified and highlighted for resource allocation (i.e., adding staff).

An evaluation of the queue size (or work-in-process) buffer volumes can also point to resource imbalances. If these factors are variable or changing, it could be effective to introduce flexibility to the process by outsourcing certain activities. Evaluating the process flow diagram interconnections - that is, the arrows between steps - as inputs and outputs can allow the process owner and analyst to evaluate "rework." If downstream processes are rejecting or otherwise returning material (such as interconnection application forms), downstream requirements or specifications might be unclear, or an opportunity for better instruction could exist.

The IREC Model Interconnection Procedures (2019) recommend that states adopt requirements to ensure that key data are publicly available. According to the procedures, certain information, published for the fair access of all stakeholders, could provide significant oversight into the conduct of interconnection procedures. IREC outlines how states could require records on interconnection queues as well as other measures regarding administrative and process performance.

The analysis tools discussed in this guide could complement these data and information. First, these analysis tools could be applied to help AGIRs and stakeholders determine the value/cost of reporting these data. From there, once the specific data set is determined, the tools could be used to manage the information for interconnection process improvement.

\subsection{Considerations for Step 1 Activities}

There are three key outputs of the Step 1 activities: (1) convening a core team of stakeholders; (2) developing a list of requirements, which should include performance metrics to inform 
maintaining and improving the interconnection rule over time; and (3) incorporating process measures, visualization, and analysis tools into structuring DER interconnection rules.

The goal of the Step 1 activities is to identify and understand the drivers, constraints, and requirements of the various stakeholders. This type of analysis is important in determining the scope of the interconnection rule. For example, if one stakeholder is a DER aggregator, the scope of the interconnection rule will likely include economic considerations, such as compensation for grid services, as well as technical considerations related to interoperability, such as communications and cybersecurity requirements. Further, it might require discussion on customer data privacy.

Different stakeholders in the DER interconnection process are motivated by different drivers and objectives. Their objectives might correspond to one or more policy, technical, or market drivers at any time. For instance, rather than being driven by a single overarching objective, jurisdictions are increasingly adopting renewable energy targets to achieve multiple interrelated objectives, such as energy security, grid modernization, greenhouse gas emissions reduction, and environmental sustainability (IRENA 2015). At the same time, some state public service commissions might be motivated by RPS goals and clean energy targets in addition to concerns for grid safety and the encouragement of new DER technologies.

Using certain capabilities, such as voltage regulation and interoperability, might have implications beyond the strict scope of IEEE Std 1547-2018 — for example, grid modernization policy goals and strategies, market strategies for enabling aggregated grid services from DERs, the integration of DERs into DER management systems or advanced distribution management systems, communications with aggregators and customer-sited devices, and cybersecurity framework and posture. Because of this, the standard expects decision makers to enable, implement, and use these technical capabilities and that the decisions shall have input not only from the area EPS operator but also from the AGIR. The AGIR might choose to solicit input from a broader set of stakeholders via public workshops and meetings.

In the revised IEEE Std 1547 (IEEE Std 1547-2018), DER capabilities for grid support of the BPS under abnormal voltage and frequency conditions are now mandatory. In most areas of the United States, enabling these capabilities has implications that extend well beyond the purview of only the area EPS operator (for example, bulk system reliability and resilience, black start). Therefore, the standard expects that coordinated discussions will take place between the area EPS operator, the AGIR, and the relevant RRCs Figure 15.

The AGIR might want to consider that energy policy and market conditions can have large impacts on the amount of DER installed capacity. Increases in DER deployment can happen more quickly, relative to the traditional planning process of most electric utilities. For example, consider the growth of distributed PV in Hawaii. Figure 10 illustrates the growth of residential and commercial PV in Honolulu, Hawaii, from 2012 through 2019. Figure 11 shows the cumulative installed capacity of residential and commercial distributed PV systems in the Hawaiian Electric Companies (HECO) service areas, which provide electricity for approximately $95 \%$ of Hawaii's population. 


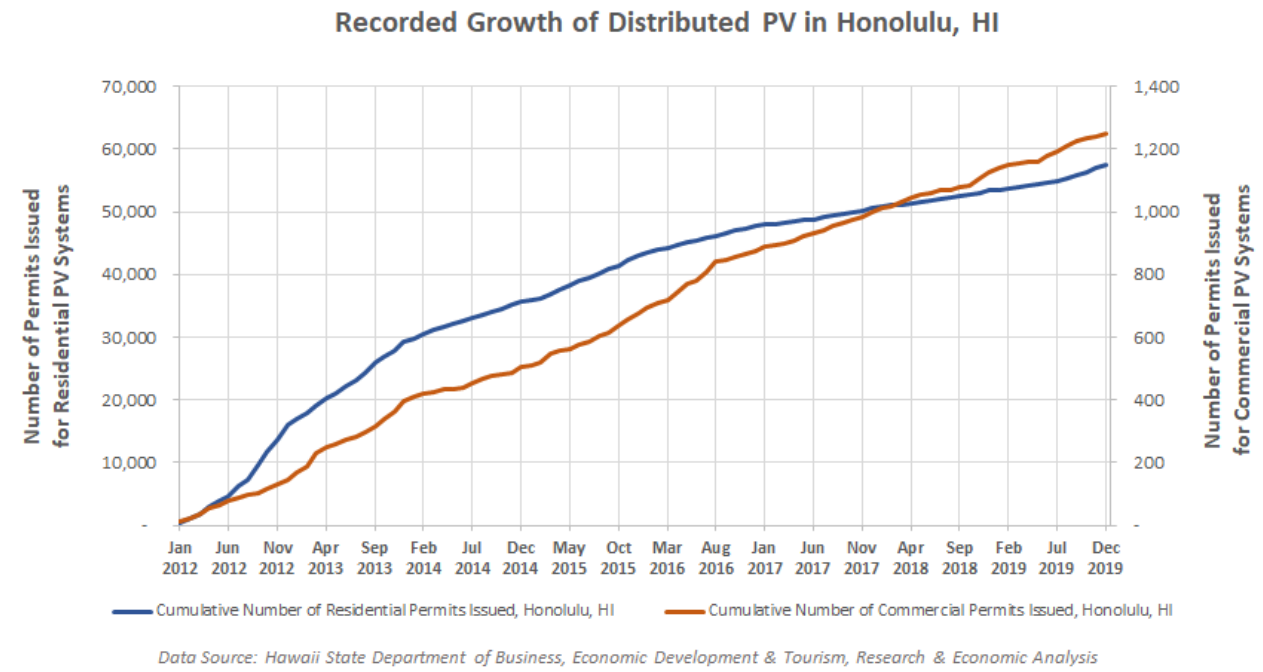

Source: Based on data from Hawaii State Department of Business, Economic Development \& Tourism, Research and Economic Analysis

Figure 10. Growth of distributed PV in Honolulu, Hawaii

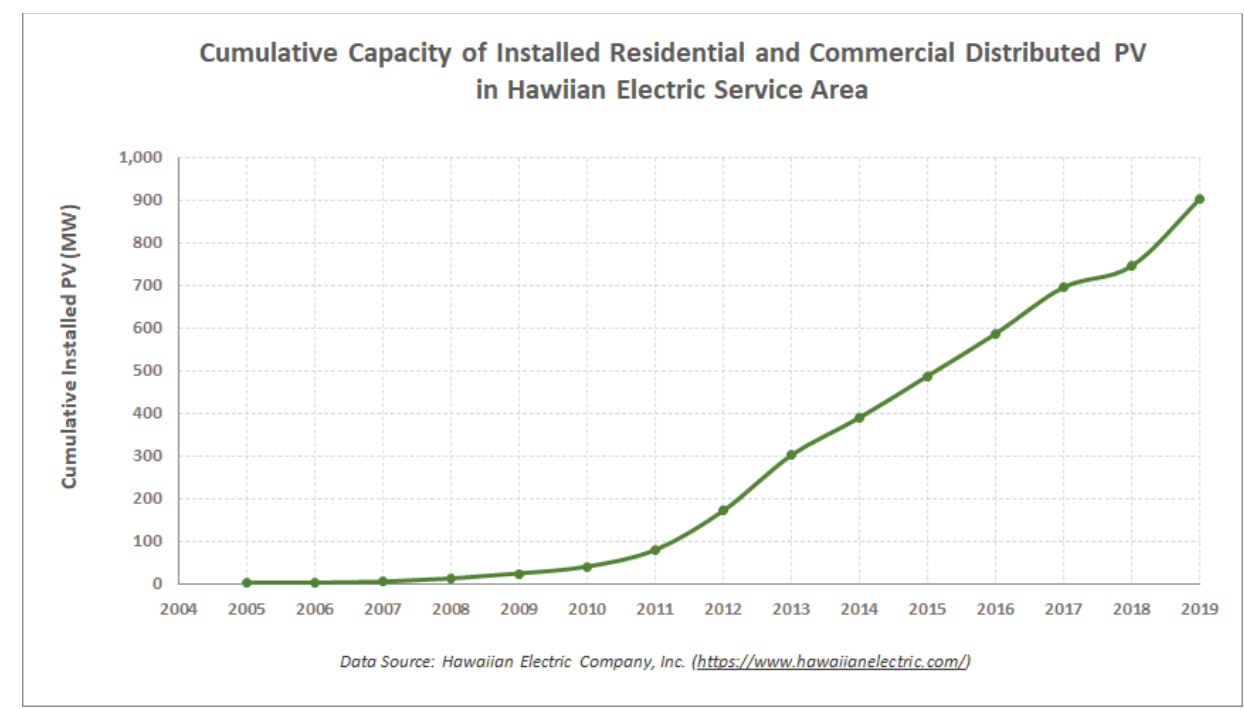

Figure 11. Cumulative capacity of residential and commercial PV in HECO service area

Ultimately, the Hawaii Public Utilities Commission and the stakeholders recognized DERs as an integral part of not only the island's energy mix but also Hawaii's grid modernization strategy. This is evidenced by HECO's Power Supply Improvement Plan of December 23, 2017, in which HECO described strategies for grid modernization, including improvements to grid infrastructure to increase DER hosting capacity (HECO 2017). These strategies were considered near-term activities as part of the overall Grid Modernization Action Plan. 
As shown from this example, the interconnection rules process could be affected by broader policy goals as well as technical issues. Successful completion of the Step 1 activities will help ensure that the interconnection rule clearly defines the necessary technical requirements and best meets the objectives of all stakeholders.

\section{State Spotlight}

In the Hawaiian Electric Companies (HECO) service areas, which include approximately 95\% of Hawaii's population, the cumulative capacity of installed residential and commercial distributed PV systems increased ninefold between 2011 and 2019. The

Hawaii Public Utilities Commission and its stakeholders recognized DERs as an integral part of Hawaii's energy mix and grid modernization strategy. In HECO's Power Supply Improvement Plan of 2017 (HECO 2017), HECO described strategies for grid modernization, including improvements to grid infrastructure to increase DER hosting capacity, including:

- Activating new and advanced inverter functions to support DER integration

- Updating operational strategies to increase distribution circuity hosting capacities

- Developing methods to use inverterbased DERs for frequency support

- Developing DER communications, monitoring, and reporting requirements to improve situational awareness and the control of DER assets

- Evaluating voltage-reactive power optimization to improve distribution circuit hosting capacity

- Adding fast frequency response contingency resources

- Adding synchronous condensers to provide reactive power for voltage support

- Adding additional research-anddevelopment activities and pilot projects to improve voltage and frequency management, situational awareness and visualization, and overall DER integration. 


\section{Step 2: Developing the Distributed Energy Resource Interconnection Rule}

\subsection{Broader Context for Distributed Energy Resource Interconnection Rules}

In addition to technical requirements, interconnection rules and procedures could include process-related steps and other requirements related to broader energy policy goals and regulations or energy market considerations. In areas with high renewable energy targets that include large shares of inverter-based resources, to the impact of these resources on the BPS also needs to be considered.

Figure 12 depicts the broader context for the DER interconnection process together with the connection between technical and nontechnical requirements. This figure also illustrates that interconnection rules fit into a broader set of technical requirements that are tailored to meet the needs of the customer's intended use of the technology as well as the requirements placed by the electric power system operator. As illustrated, IEEE Std 1547-2018 is intended to be used in conjunction with other standards to address other important aspects of interconnection. The adoption of technical standards such as IEEE Std 1547-2018 can help to reduce the overall cost of implementing technologies in many ways, including increasing the uniformity of design, minimizing costly custom solutions, and sharing best practices.

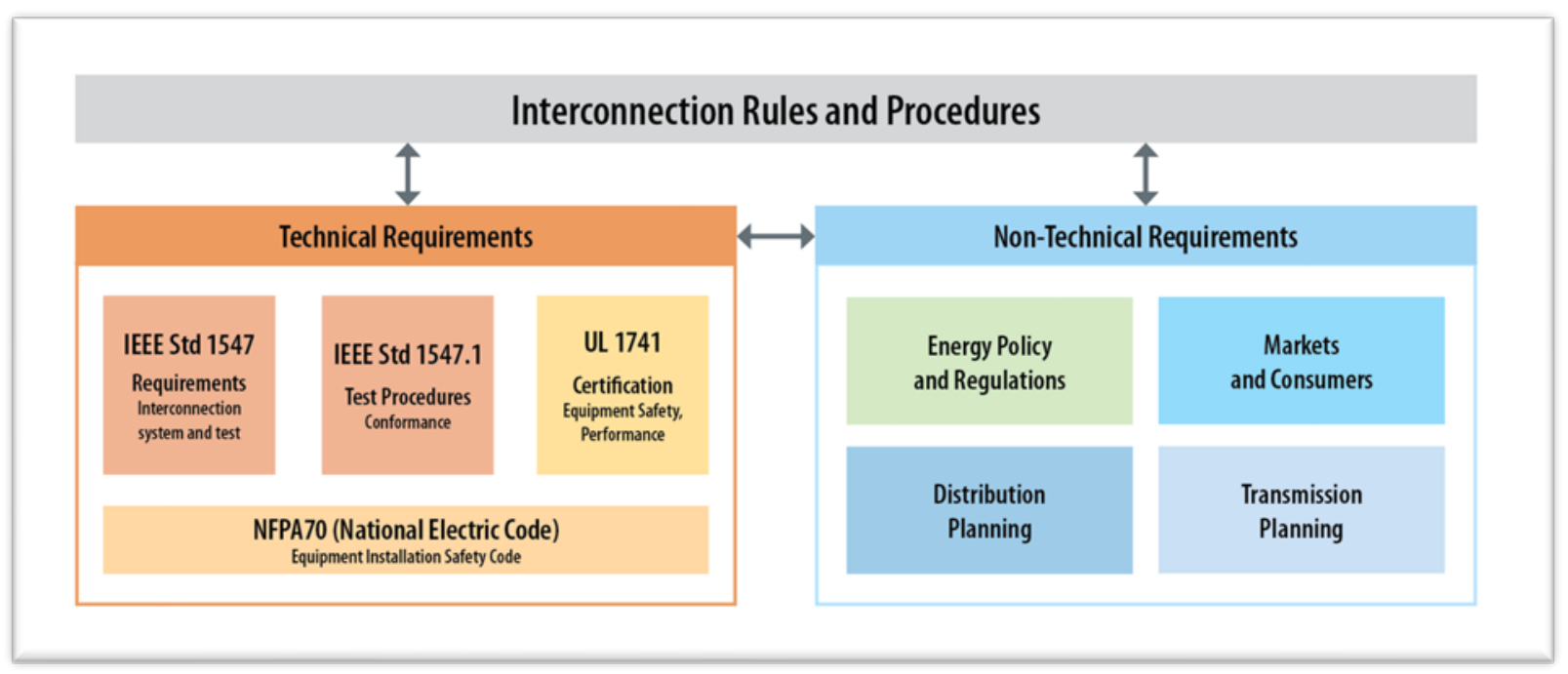

Figure 12. Broader context for DER interconnection

\subsection{Interconnection Process Foundations}

DER interconnection processes are developed at the national and state levels and are influenced by energy policies and market regulations in addition to transmission and distribution planning results. At the national level, FERC provides technical and legal guidance via the SGIP and the SGIA for interconnecting DERs up to $20 \mathrm{MW}$ to the electric grid for projects subject to FERC's jurisdiction. 
Because purely intrastate distribution grids are generally not considered to be included in “interstate commerce," FERC's standards generally do not apply to distribution-level interconnection, which is regulated by the public service commission (DSIRE 2016). Many states and utilities, however, have used FERC's standards as a guiding model to develop their rules for distribution-level interconnections.

In November 2013 and September 2014, with Order 792 and Order 792-A, FERC revised the small generator interconnection standards for DERs up to $20 \mathrm{MW}$. These standards revised FERC Order 2006 from May 2005. FERC concluded that the reforms adopted in the final rule will reduce the time and costs required to process small generator requests for interconnection customers, maintain reliability, increase energy supply, and remove barriers to the development of new DERs (FERC 2013).

Key changes implemented as part of the revised FERC standards include:

- Provision of a pre-application report for the interconnecting customer

- Revision of the 2-MW threshold for qualification in the fast-track process

- Revision of customer options for supplemental review

- Inclusion of energy storage devices as part of DERs interconnecting to the grid

- Revision of the SGIP Facilities Study Agreement.

At the state level, public service commissions establish interconnection rules that customers and utilities must adhere to while interconnecting a DER system. Interconnection rules, much like net metering policies, vary from one state to another, and utilities can have their own additional procedures for interconnecting DERs to their network. For example, in December 2000, the California Public Utilities Commission established Rule 21, which introduced a screening process for streamlining interconnection process reviews and the provision of procedural timelines for expediting the interconnection process. Most state rules today have time-bound process workflows for interconnecting DERs to the grid and incorporate a fast-track review in addition to the default study process. Additionally, AGIRs are constantly revising existing interconnection processes to address bottlenecks that cause process delays and hinder the adoption and integration of DERs with the grid.

\subsection{Determining Interconnection Technical Requirements}

Interconnection technical requirements are influenced by industry standards, such as IEEE Std 1547-2018. Other important requirements are dictated by the utility because of operational needs and practices or electric circuit configuration. Energy policy and regulations can result in additional technical requirements. 


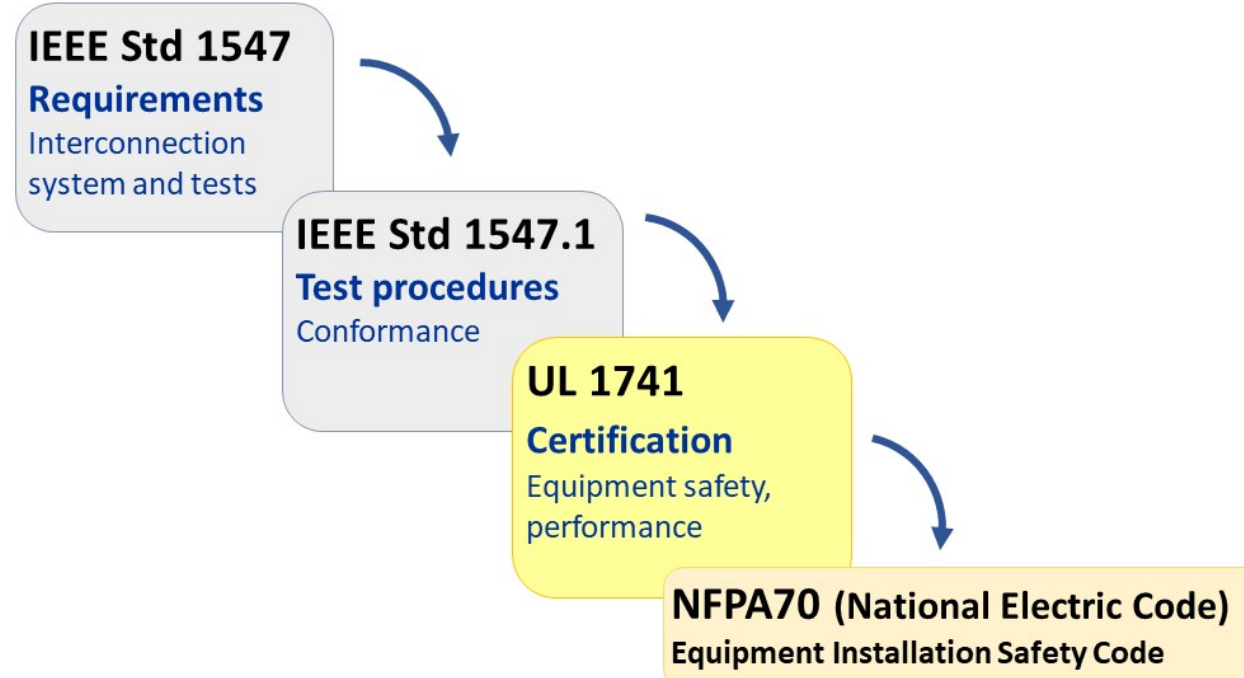

Figure 13. IEEE Std 1547-2018 and related standards

IEEE Std 1547-2018 provides the "uniform criteria and requirements relevant to the performance, operation, testing, safety considerations, and maintenance of the interconnection" (IEEE 2018). IEEE Std 1547.1 provides the test procedures to verify the technical requirements, UL 1741 is used to certify the equipment's safety and functional capabilities, and NFPA 70 (National Electric Code, NEC) prescribes installation requirements. Together, as illustrated in Figure 13, these standards form the backbone of the interconnection requirements, certification, and installation of DERs to the distribution grid in the United States. In broad terms, the distribution system "includes all parts of an electricity utility system between bulk power sources and the consumers' service-entrance equipments" (Beaty and Fink 2007). A drawing of a typical distribution circuit is shown in Figure 14.

Different types of DERs have inherent characteristics and therefore might require unique considerations for interconnection. Overall, the interconnection requirements are intended to meet the needs of all DERs. A summary of common concerns is given in the following section. 


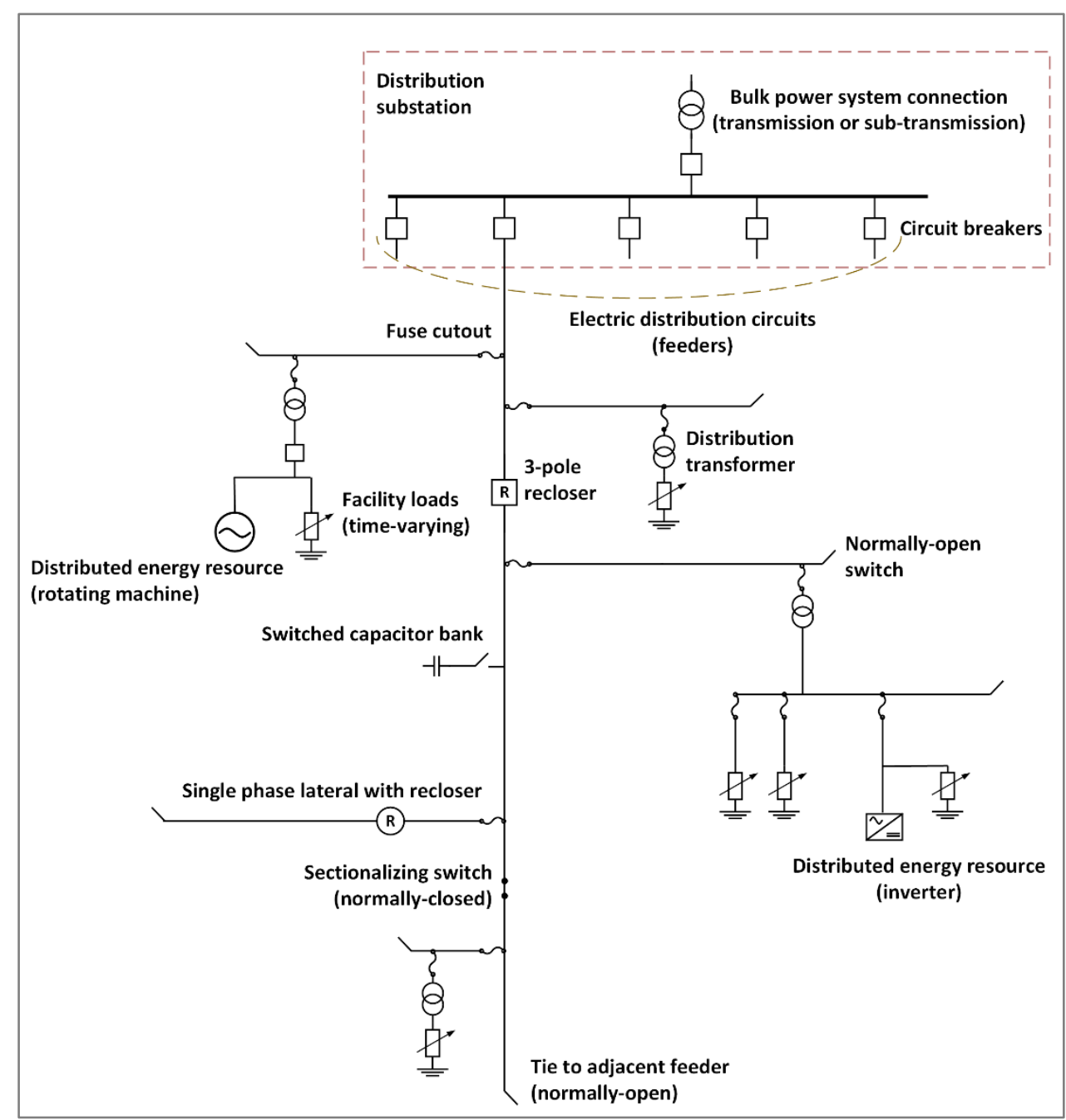

Figure 14. One-line diagram of an example distribution feeder, adapted from Beaty and Fink (2007)

Distribution utilities name three items as top priorities in providing electric service to their customers: (1) delivering reliable and good-quality electric service while (2) ensuring the safety of the general public and utility workers and (3) at an affordable cost. Another important goal is to avoid damage to electric distribution and customer equipment. Because anything that could negatively affect these things will be a utility concern, it is important to understand that the requirements in IEEE Std 1547-2018 address these priorities.

\subsubsection{Safety}

The safety of electric utility workers and the general public is a primary utility concern. Every day, utility workers perform high-risk activities, such as working nearby or in contact with energized high-voltage systems, often at extreme heights or in confined spaces. The U.S. Bureau of Labor Statistics consistently ranks electrical line work as one of the most dangerous jobs in the United States. Although IEEE Std 1547-2018 is not a "safety standard," it was written with the aim of minimizing the chances of DERs increasing risk to the public or electric workers. This was done by including performance requirements that can be coordinated with utility protection equipment. DER anti-islanding (unintentional) protection and response to short-circuit fault and open-phase conditions are part of the core requirements of IEEE Std 1547-2018. 
As a result of the cost and timing impact that the screening and mitigation have on DER development, stakeholders should work to ensure that:

1. The risk of islanding is being assessed appropriately.

2. The methods for screening for that risk reflect the latest and most credible research on island formation.

3. The mitigations implemented (if necessary) are both effective and cost conscious.

4. The costs of the mitigations are assessed on the appropriate party(ies).

IEEE Std 1547-2018 is unequivocal on detecting and mitigating unintentional islanding, requiring DERs to cease to energize and trip within 2 seconds of the formation of an island. Consequently, in each category listed, there are a set of questions that need to be explored and policy choices that the AGIRs might want to make to ensure appropriate treatment of islanding risk and underlying utility guidance. For example, when exploring EPS system-level approaches to dealing with island risk - such as direct transfer trip - it might be worthwhile to question the assumptions that lead to mitigation in the first place.

In many cases, utility requirements and practices are dictated by national laws and regulations, such as those promulgated by the Occupational Safety Health Administration, the National Fire Protection Agency (e.g., NFPA 70, also known as the NEC), IEEE (e.g., National Electrical Safety Code), and UL. ${ }^{12}$ Additional requirements might be imposed by state and local jurisdictions.

DERs, by definition in IEEE Std 1547-2018, are a source of electric power that include both generators and energy storage technologies capable of exporting active power to the grid. DERs are typically installed at a customer site that is downstream of the utility substation, the main source of energy for the entire distribution line. Under certain conditions, DERs constitute a possible source of electrical energy that can feed energy back (back-feed) into the distribution system. IEEE Std 1547-2018 contains specific requirements that govern back-feed-for example, in the clauses on unintentional islanding. An electric utility might also impose other requirements based on circuit configuration or operational practice.

Requirements that fall under protection (i.e., safety) are built in - that is, the DER inherently has these capabilities, and very few settings can be changed. The few settings that can be changed are to allow utilities to coordinate with area EPS protection systems.

\subsubsection{Reliable Operation and Good-Quality Electric Power}

IEEE Std 1547-2018 raises the bar for DERs, especially inverter-based DERs, to perform as "good citizens" of the grid. Requirements for DER output power quality are quantifiable and include limits on the injection of DC and harmonics-causing distortion, voltage fluctuations,

\footnotetext{
${ }^{12}$ In the United States, UL 1741 is the equipment safety standard that all inverters and converters must meet to be certified. UL 1741 is harmonized with IEEE Std 1547-2018 and with IEEE Std 1547.1, the testing substandard in that group. UL 1741 ensures that every inverter is manufactured, programmed, and tested to safely perform its allowed functions. Inverters without the proper UL 1741 label should never be permitted or operated on any electric distribution power system.
} 
contributions to overvoltage at the point of common coupling, ${ }^{13}$ and new synchronization tolerances. Because EPS can be harsh environments, performance requirements for DER "immunity and withstand" (i.e., interconnect integrity) are included in IEEE Std 1547-2018. Requirements that fall under this topic are built in - that is, the DER inherently has these capabilities.

The term interconnect integrity is used to specify requirements for DER protection from electromagnetic interference, surge withstand, and requirements for the DER paralleling device. In addition, other requirements include coordination with area EPS reclosing and requirements for DERs on secondary and spot networks.

With respect to DER interconnection, power quality ${ }^{14}$ is used to specify the requirements for energy delivery "quality." IEEE Std 1547-2018 specifies requirements to address several types of power quality phenomena. These include limitation of DC injection, limitation of DERinduced voltage fluctuations (rapid voltage changes, flicker), limitation of current distortion, and limitation of overvoltage contribution (during one fundamental frequency period, cumulative instantaneous).

\subsubsection{Protection of Electric Power System and Customer Equipment}

IEEE Std 1547-2018 specifies requirements to address the protection of EPS and customer equipment. These include requirements for what the standard terms criteria for "enter service" and "synchronization." These requirements specify that (1) the DER can enter service only when the EPS voltage and frequency are within acceptable ranges; (2) when entering service, the DER must increase power in a gradual manner to avoid overly large step changes in active power; (3) the DER can enter service only when the voltage, frequency, and phase angle are synchronized within acceptable ranges; and (4) the DER grounding scheme must be coordinated with the ground fault protection of the area EPS.

Under this set of requirements, several settings can be changed within specified ranges. There are provisions, for example, to align the trip settings at the DER devices with substation and feeder equipment (i.e., coordination). The Clause-by-Clause Summary of Requirements in IEEE Standard 1547-2018 (Narang et al. 2020) summarizes default protection settings and optional configurations.

${ }^{13}$ IEEE Std 1547-2018 defines the point of common coupling as the point of connection between the area EPS and the local EPS, which is contained entirely within a single premise or a group of premises.

${ }^{14}$ In some forums, power quality and reliability are used interchangeably; however, these terms can have different definitions. A definition for power quality given in Electrical Power Systems Quality is "[a]ny power problem manifested in voltage, current, or frequency deviation that results in failure or misoperation of customer equipment" (Dugan et al. 2003). Dugan and coauthors point out that power quality is essentially an issue that affects consumers. Reliability, on the other hand, is a concept used to describe issues that affect the power system. A definition for reliability can be found in NERC's document Definition of "Adequate Level of Reliability," which states that "[o]perating reliability is the ability of the electric power system to withstand sudden disturbances such as electric short circuits or unanticipated loss of system components" (NERC 2007). Confusion might occur because for the distribution system, reliability is measured by indices that indicate the effect on customers (these are the "reliability" indices SAIFI, SAIDI, CAIDI, and MAIFI). 
Typically, electric power systems in the United States are considered very reliable; however, conditions do occur that put the system in an abnormal state. IEEE Std 1547-2018 contains requirements for DER responses under these conditions. These include DER responses to area EPS short-circuit faults and open-phase conditions, DER tripping requirements for over- and undervoltage conditions, and DER tripping requirements for over- and underfrequency conditions.

The standard also requires DERs to have capabilities that can be used to help support the grid under both normal and abnormal conditions. These include ride-through of voltage disturbances (including dynamic voltage support during low- and high-voltage ride-through), ride-through of frequency disturbances (including the capability to adjust power as a function of frequencyfrequency droop during low- and high-frequency ride-through), ride-through of rate of change of frequency, and ride-through of voltage phase angle changes.

Interconnection requirements could include additional elements depending on the utility or local jurisdiction needs and practices.

\subsubsection{Affordable Cost}

Utility personnel - who participate in standards development and/or rely on them to specify power systems equipment - understand the strategic benefits of technical standards to reduce costs through normative performance. Further, uniform and transparent technical requirements can improve interconnection-application processing efficiencies and reduce distributed generation "soft costs" (i.e., non-hardware costs). These effects on EPS costs are an important benefit of adopting and implementing IEEE Std 1547-2018.

\subsubsection{Equipment Installation}

The NEC is the national electrical code to which residential and commercial DERs should be designed, built, and operated. All DERs should be designed to follow NEC requirements and, when completed, they should be inspected to ensure that all NEC requirements have been followed. The NEC contains several articles specific to PV, such as sections 690.4 (B), 690.35 (G), and 705.4. It also contains many articles specific to the design of the non-inverter electrical systems, such as conductors and conduits, fuses and other protection, and grounding. The DER owner is responsible for ensuring that the DER design and installation meet the technical requirements and comply with, as applicable, the NEC.

\subsection{Considerations for Utilization of New Capabilities Enabled by IEEE Std 1547-2018}

IEEE Std 1547-2018 specifies the requirements for capabilities that DERs must have. Formal action is needed to adopt the standard and to use the new capabilities. The following discussion provides considerations for the utilization of some key capabilities. 


\subsubsection{Distribution Voltage Management ${ }^{15}$}

One of the most important responsibilities for a utility is to maintain the voltage at the electrical outlet within acceptable limits (i.e., ANSI C84.1). Yet, in a typical distribution circuit, with no reverse power flow, voltage decreases as the distance from the substation increases according to the length of the circuit (i.e., electrical distance), the characteristics of the electrical distribution wires, and the amount of connected load. To manage these factors, a utility could use various types of equipment that regulate the voltage to within the acceptable range. Typical voltage regulation equipment includes voltage regulators at the substation or anywhere along an electric distribution line, voltage regulating capacitors, and load tap changers.

Modern DER inverters have this voltage regulating capability and can play an important role in helping to regulate distribution voltages by providing both active and reactive power support. Injecting reactive power serves to increase the local voltage, whereas absorbing reactive power decreases the local voltage. Inverters can be used to address overvoltage issues that are commonly observed on numerous circuits and can expand the hosting capacity.

IEEE Std 1547-2018 specifies capabilities for regulating voltage by reactive power control and active power control. Modes include:

- Constant power factor mode. In this mode, the DER operates at a constant power factor, modulating reactive power to hold the ratio of active and reactive power constant as active power changes. This mode, at unity power, is the default factory-setting mode.

- Voltage-reactive power mode (volt-volt ampere reactive, or volt-VAR). In this mode, the DER actively controls its reactive power output as a function of voltage, which typically acts to push the local voltage back toward nominal. This mode is designed so that the DER supplies or absorbs reactive power (e.g., VAR) only when needed to mitigate voltage deviations.

- Active power-reactive power mode (watt-VAR): In this mode, the DER actively controls its reactive power output as a function of the active power output.

- Constant reactive power mode: In this mode, the DER maintains a constant reactive power output.

- Voltage-active power mode (volt-watt). In this mode, the DER actively limits its active power as a function of the voltage. This mode can be used to reduce the prevalence of very high voltages and could be enabled in conjunction with other modes, such as voltvar mode.

These capabilities are intended for normal grid conditions. As noted, different types of DERs could have different inherent capabilities, and therefore IEEE Std 1547-2018 introduces the

\footnotetext{
${ }^{15}$ ANSI C84.1 is adhered to by most electrical utilities and is used to set guidelines for maintaining voltage levels within tolerances that will support the integrity of the utilization equipment served by the electric power system. ANSI C84.1 Range A is most often used to set the parameters to "nominal voltage +/- 5\%." Equipment will perform best when operated inside Range A, and it could be damaged if operated outside that range for an extended time (see ANSI C84.1 for specifics). PV systems have the potential to impact voltage levels, typically causing higher voltages, and ANSI C84.1 helps define the range for the proper operation of all utilization equipment and distributed generation (NEMA 2016).
} 
concept of normal operating performance category, defined as "participation of the DER in the voltage and reactive power management of the Area EPS" (IEEE 2018, Appendix B).

The utilization of these capabilities is at the discretion of the area EPS operator, as the entity typically responsible for maintaining the distribution grid voltage. In certain jurisdictions, however, these capabilities could be considered grid services that either the customer or a third party could provide to the utility. In such a case, the list of potential stakeholders expands beyond the utility and the consumer, and the relationship between the utility and the consumer might also change. An AGIR might want to consider whether to provide specific technical or process requirements or guidance on implementation. Market or policy considerations such as the incentivization of a specific type of DER; the long-term intended purpose and use of DERs; grid integration, such as managing characteristics of the area EPS; the development of specific market segments; grid modernization investment plans; remote communications and cybersecurity; the choice of communications protocol; and market structure could all be relevant to these decisions and are factors that could influence the selection of the normal operating performance category.

In the new standard, voltage regulation is disabled by default; therefore, states and utilities will need to determine if and when voltage regulation functions should be turned on, which function should be used, which settings should be used, and how enabling these functions will interact with interconnection rules. 


\subsubsection{Support for Bulk Power System Reliability}

At lower penetration levels, the impact of DERs might not be significant on the BPS or transmission-distribution interface. As the DER penetration increases, however, issues related to transmission line loading, grid voltage, and system frequency during normal and disturbed operations could be a concern for the BPS. AGIRs need to ensure that a collaborative effort is made with the utilities, DER experts, and the RRC to identify the risks to the BPS, model them appropriately, and implement suitable measures to mitigate them.

The response of aggregate DERs to abnormal voltage and frequency conditions contributes to the stability of the BPS. According to IEEE Std 1547-2018, abnormal conditions occur outside the "continuous operating region" and are mitigated, or at least not complicated, by voltage and frequency ride-through capabilities. The voltage disturbance ridethrough requirements and frequency-related settings of IEEE Std 1547-2018 provide sufficient robustness to expected BPS grid disturbances and are an important component of BPS stability as the penetration of DERs continues to increase (NERC 2020).

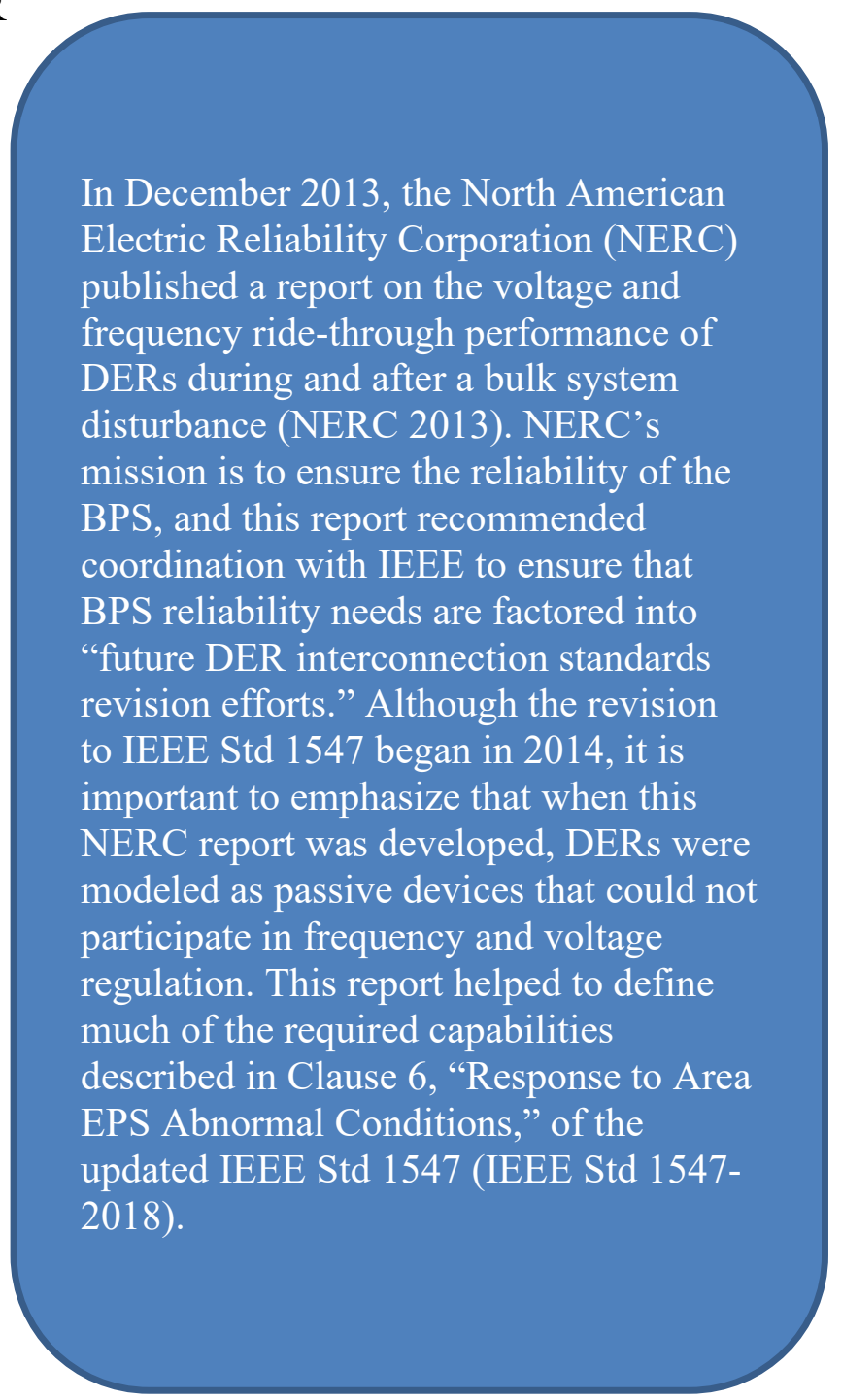




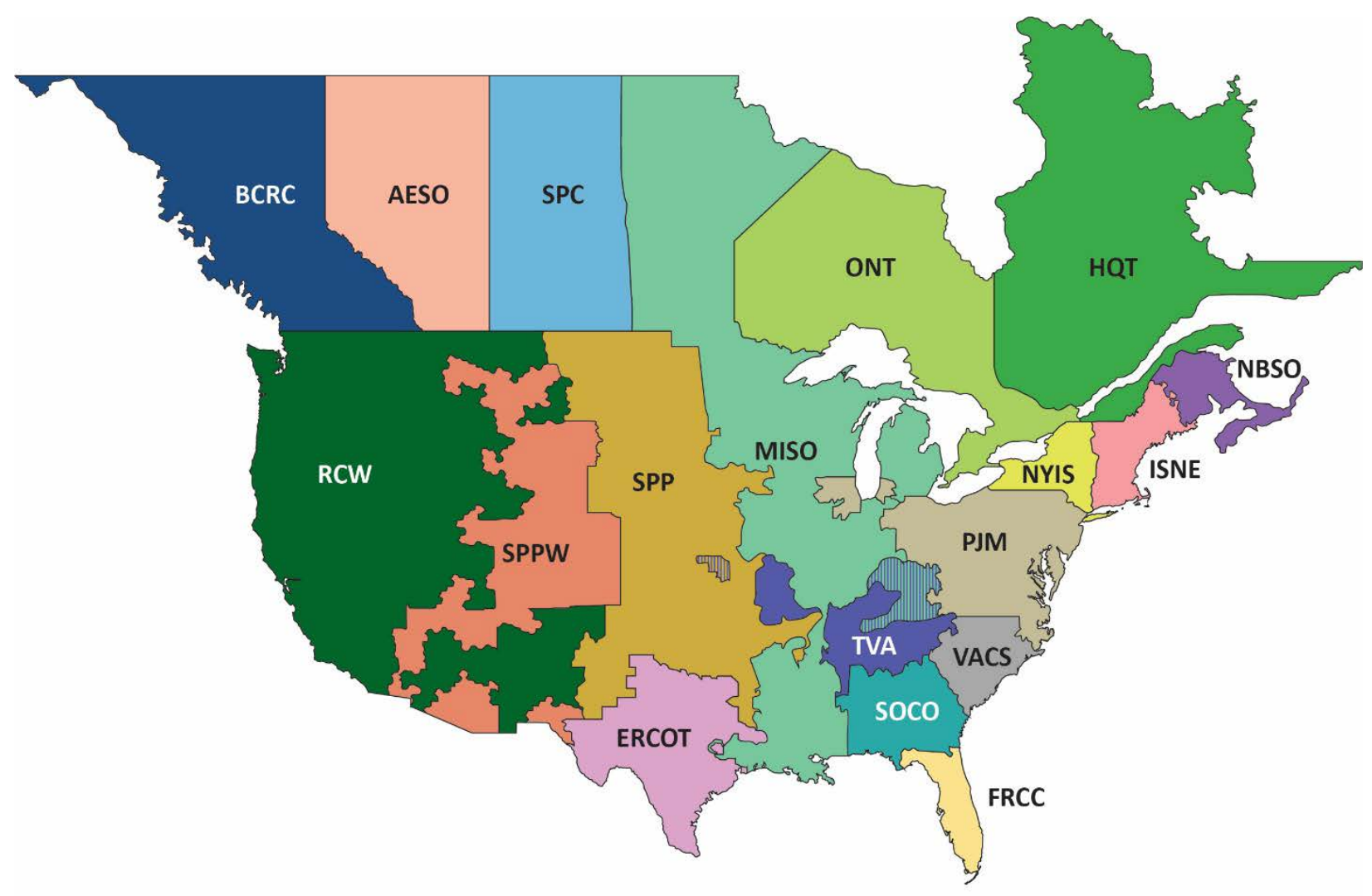

Source: NERC, reprinted with permission ${ }^{16}$

Figure 15. Regional reliability coordinators

Because IEEE Std 1547-2018 seeks to address bulk system reliability issues, especially related to voltage and frequency ride-through, AGIRs should strongly consider establishing contact with the RRC involved in managing and operating the BPS early in the interconnection update process and finding the right people to provide input; and seeking input on (1) DER impact analysis efforts and (2) existing BPS frequency and/or voltage concerns. Table 2 lists the RRCs that AGIRs should involve, depending on their jurisdiction. (Note: Some jurisdictions might have more than one interested RRC.) Table 3 summarizes the points of reference in IEEE Std 1547-2018 that cover BPS-specific interests and decisions.

\footnotetext{
16 This information from the North American Electric Reliability Corporation's website is the property of the North American Electric Reliability Corporation and is available at (https:/www.nerc.com/pa/rrm/TLR/Pages/ReliabilityCoordinators.aspx). This content may not be reproduced in whole or any part without the prior express written permission of the North American Electric Reliability Corporation.
} 
Table 2. Regional Reliability Coordinators

\begin{tabular}{lll}
\hline Name & Address & Telephone \\
\hline ERCOT & ERCOT ISO, 7620 Metro Center Dr., Austin, TX & $512-225-7000$ \\
\hline FRCC & $\begin{array}{l}\text { Florida Reliability Coordinating Council, 3000 Bayport Dr., STE 600, } \\
\text { Tampa, FL }\end{array}$ & $813-289-5644$ \\
ISNE & ISO New England Inc., 1 Sullivan Rd., Holyoke, MA & $413-535-4000$ \\
\hline MISO & $\begin{array}{l}\text { Midcontinent Independent System Operator, Inc., 720 West City } \\
\text { Center Dr., Carmel, IN }\end{array}$ & $317-249-5400$ \\
NYIS & New York Independent System Operator, 10 Krey Blvd., Rensselaer, & $518-356-6000$ \\
\hline RCW & RY & \\
\hline PJM & Reliability Coordinator West, 250 Outcropping Way, Folsom, CA & $833-888-9378$ \\
\hline SOCO & $\begin{array}{l}\text { Southern Company Services, Inc., 30 Ivan Allen Jr. Blvd. NW, Atlanta, } \\
\text { GA }\end{array}$ & $404-506-5000$ \\
\hline SPP/SPPW & Southwest Power Pool, 201 Worthen Dr., Little Rock, AR 72223 & $501-614-3200$ \\
\hline TVA & Tennessee Valley Authority, 400 W. Summit Hill Dr., Knoxville, TN & $865-632-2101$ \\
\hline VACS & VACAR South, 550 South Tryon Str., Charlotte, NC & $800-777-9898$ \\
\hline
\end{tabular}

Table 3. Touchpoints with BPS Entities

Source: Narang et al. (2020)

\begin{tabular}{|c|c|c|}
\hline Clause & Description & Key Decisions \\
\hline 6.1 & $\begin{array}{l}\text { Assignment of abnormal operating } \\
\text { performance categories }\end{array}$ & $\begin{array}{l}\text { The area EPS operator, as guided by the AGIR, in } \\
\text { coordination with the RRC, specifies the required } \\
\text { abnormal operating performance category. The } \\
\text { area EPS operator specifies trip settings. }\end{array}$ \\
\hline $\begin{array}{l}\frac{4.10}{\text { Enter }} \\
\text { Service }\end{array}$ & Performance during entering service & $\begin{array}{l}\text { If a local EPS with aggregate DERs equal to or } \\
\text { greater than } 500 \mathrm{kVA} \text { is allowed to increase the } \\
\text { active power in steps greater than } 20 \% \text { of the } \\
\text { nameplate active power rating, this shall require } \\
\text { approval of the area EPS operator in coordination } \\
\text { with the RRC. }\end{array}$ \\
\hline$\frac{6.4}{\text { Voltage }}$ & $\begin{array}{l}\text { Mandatory voltage and frequency } \\
\text { tripping requirements }\end{array}$ & $\begin{array}{l}\text { Guidance on voltage/frequency trip settings } \\
\text { different from default values and within specified } \\
\text { ranges of allowable settings }\end{array}$ \\
\hline $\begin{array}{l}\frac{6.5}{\text { Frequency }} \\
\text { (Tripping) }\end{array}$ & $\begin{array}{l}\text { Coordination with area EPS } \\
\text { overfrequency and underfrequency } \\
\text { protection }\end{array}$ & $\begin{array}{l}\text { Guidance and coordination on occasionally and } \\
\text { selectively used overfrequency/underfrequency trip } \\
\text { settings of area EPS protective equipment }\end{array}$ \\
\hline $\begin{array}{l}\frac{6.5}{\text { Frequency }} \\
\text { (Ride- } \\
\text { through) }\end{array}$ & $\begin{array}{l}\text { Frequency-droop (frequency-power) } \\
\text { operation }\end{array}$ & $\begin{array}{l}\text { Guidance on adjustments to the frequency-droop } \\
\text { (frequency-power) operation }\end{array}$ \\
\hline
\end{tabular}




\subsubsection{Voltage and Frequency Ride-Through}

With the latest revision to IEEE Std 1547, DERs are required to have capabilities that can be used to improve resilience at both the distribution system and the BPS under abnormal voltage and frequency conditions. These capabilities are intended to be coordinated with settings and requirements typically given by the utility as well as BPS operators and reliability coordinators. The use of these capabilities involves considering not only the reliability of the BPS but also the protection of the DERs; therefore, the standard includes functions in the form of mandatory tripping requirements as well as abnormal voltage and frequency ride-through requirements. Settings for over- and undervoltage and over- and underfrequency are specified in the standard, as are ranges within which these settings can be adjusted to meet local requirements.

Ride-through requirements are also specified. To allow for differences in DER types, the voltage ride-through requirements apply to three types (categories) of DERs: the abnormal operating performance categories I through III. Figure 17 shows the various settings. Frequency ridethrough requirements are harmonized among all DERs. Figure 18 shows the frequency ridethrough settings.

Note that to date there has been one errata and one amendment to IEEE Std 1547-2018 that affect bulk power support-related functions. These can be found at: http://standards.ieee.org/findstds/errata/1547-2018 errata.pdf and https://standards.ieee.org/content/ieee-standards/en/standard/1547a-2020.html. 
Illustrative Comparison of Voltage Ride Through Capabilities - Category I, II, III

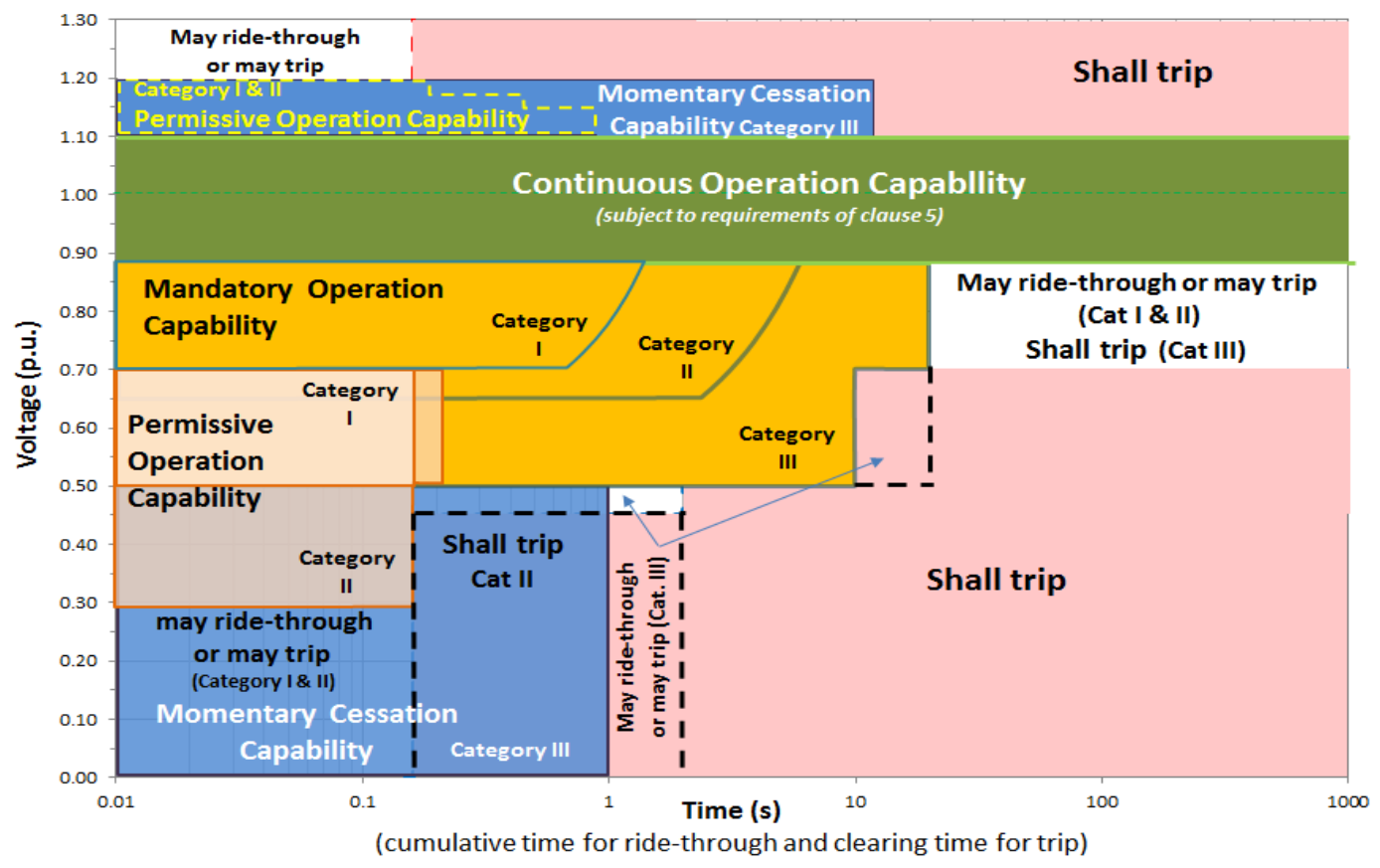

Figure based on IEEE 1547-2018 (Figs. H.7, H.7, H.8)

Figure 16. Illustrative comparison of voltage ride-through capabilities for category I, II, and III DERs

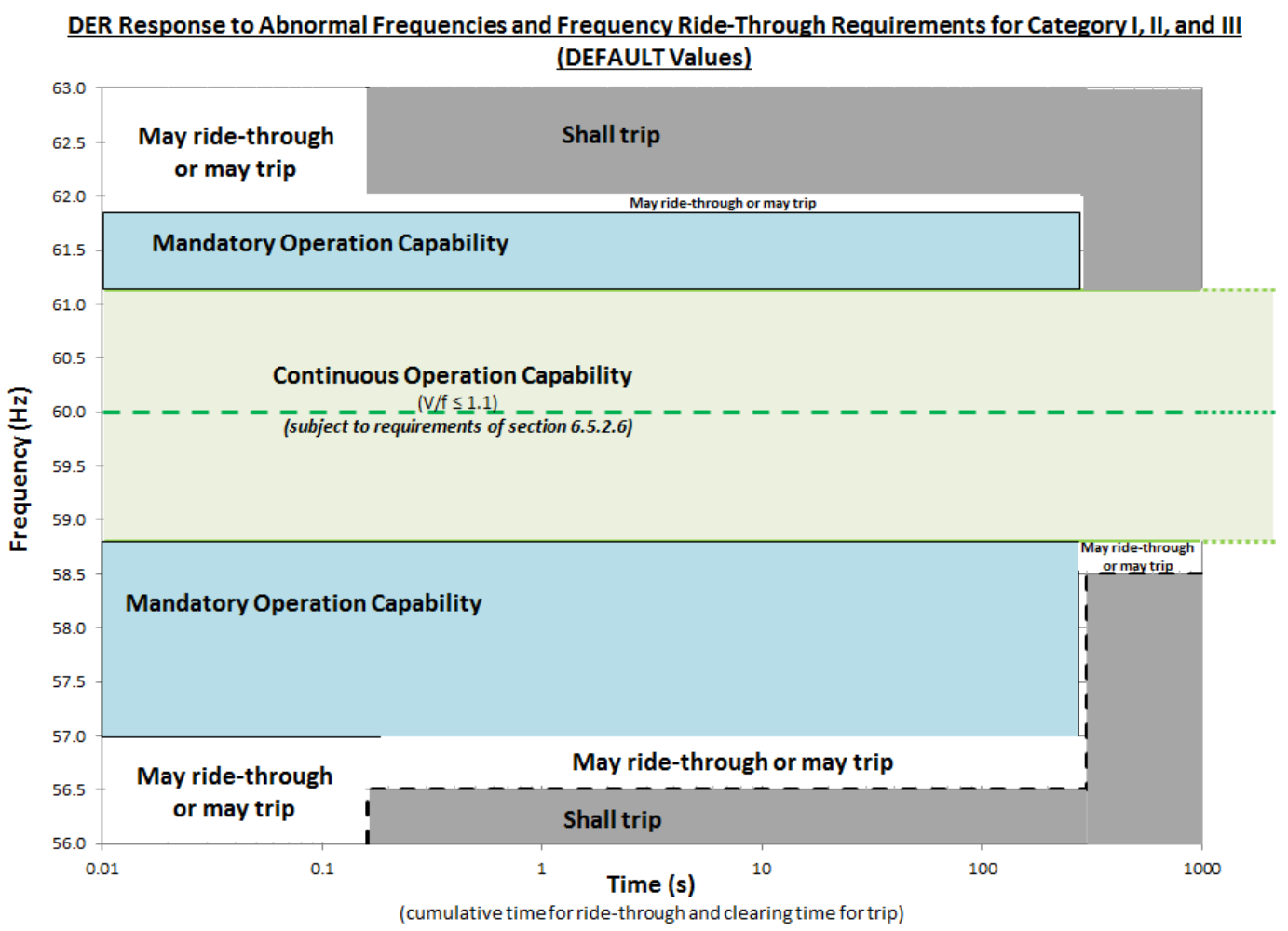

Figure based on IEEE 1547-2018 (Fig. H.10)

Figure 17. Illustrative figure showing frequency ride-through requirements for all DERs 


\subsubsection{Interoperability}

Interoperability is the capability of two or more systems to externally exchange and use information securely and effectively (IEEE 2018). Interoperability can improve situational awareness, control capabilities, and customer participation. These features also allow the DER inverter to have provisions for remote monitoring and control. IEEE Std 1547-2018 mandates certain interoperability capabilities; however, as represented in Figure 18, how they are implemented, recorded, and reported is determined by local jurisdictions and should be addressed in those processes and procedures (such as interconnection agreements).

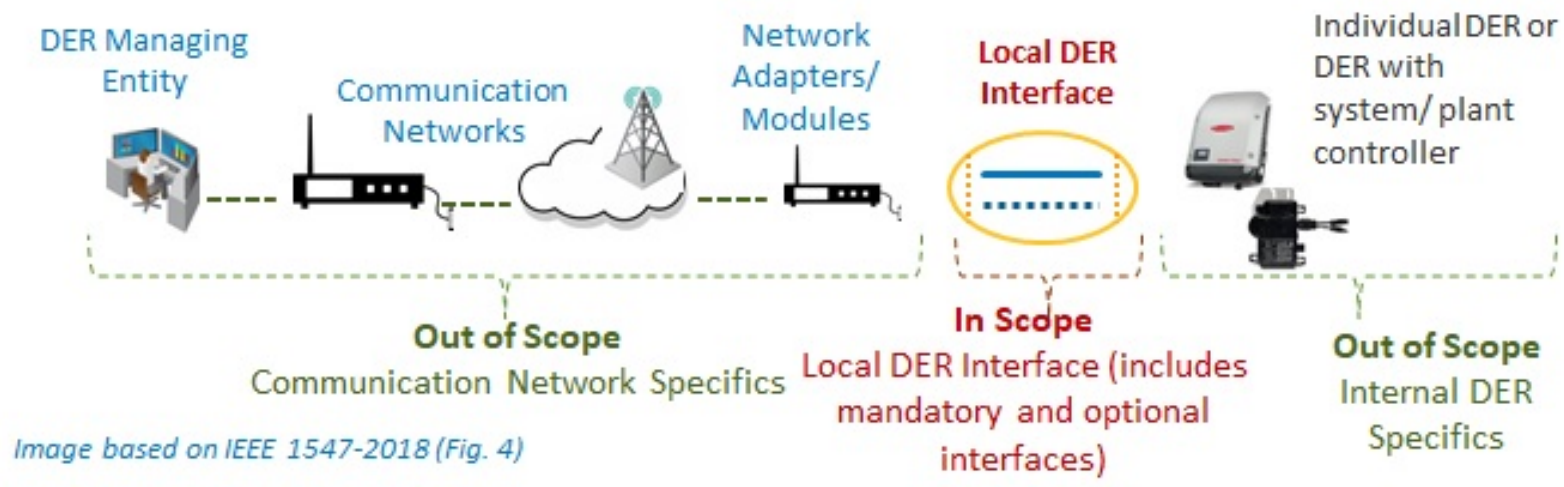

Source: Based on IEEE Std 1547-2018 (Fig. 4)

Figure 18. Scope of IEEE Std 1547-2018 power and communications

Communications and information protocols were not addressed in the prior version of IEEE Std 1547 and were left for utilities and DER developers to negotiate based on system needs. This created challenges for the equipment suppliers, who traditionally used proprietary protocols within their equipment and had little guidance on required protocols, and for utilities, who frequently use a combination of communications and information protocols. IEEE Std 15472018 brings new requirements for communications protocols that must be available at the local DER communications interface (see Figure 19), and the DER must support one of the following:

- SunSpec Modbus

- IEEE Std 1815 (Distributed Network Protocol 3)

- IEEE Std 2030.5 (Smart Energy Profile 2).

If enabled, interconnection rules will need to specify which DERs will be required to integrate with communications systems and which communications protocol the utilities will use at the DER communications interface. IEEE Std 1547-2018 provides a standardization of the local DER communications interface and protocols, but it does not specifically address the external communications channel. These decisions are left for the AGIR and area EPS operator. The following questions can inform the decision-making processes related to interoperability (Ingram, Mahmud, and Narang 2021):

- What are the use cases for interoperability?

- What is the expected timeline - for example, when might a communications and control system be needed?

- What performance level(s) might be required to support planned applications?

- Which DERs (e.g., types, size) will be integrated? 


\subsubsection{New Capability for Intentional Islanding}

In the past, intentional islanding - a condition in which DERs continue to supply power to local loads during a utility failure (i.e., microgrid) — was not addressed by IEEE Std 1547-2018 because the formation of "unintentional" islands posed risks to both the equipment and human safety. Advancements in DERs and sensing technology have mitigated these risks and therefore the revised standard now addresses intentional islanding.

IEEE Std 1547-2018 defines an intentional island as "[a] planned electrical island that is capable of being energized by one or more Local EPSs. These (1) have DER(s) and load, (2) have the ability to disconnect from and to parallel with the Area EPS, (3) include one or more Local EPS(s), and (4) are intentionally planned" (IEEE 2018).

The standard specifies requirements for intentional islands configured either as a "facility island" or an "area EPS island." These configurations are illustrated in Figure 19.

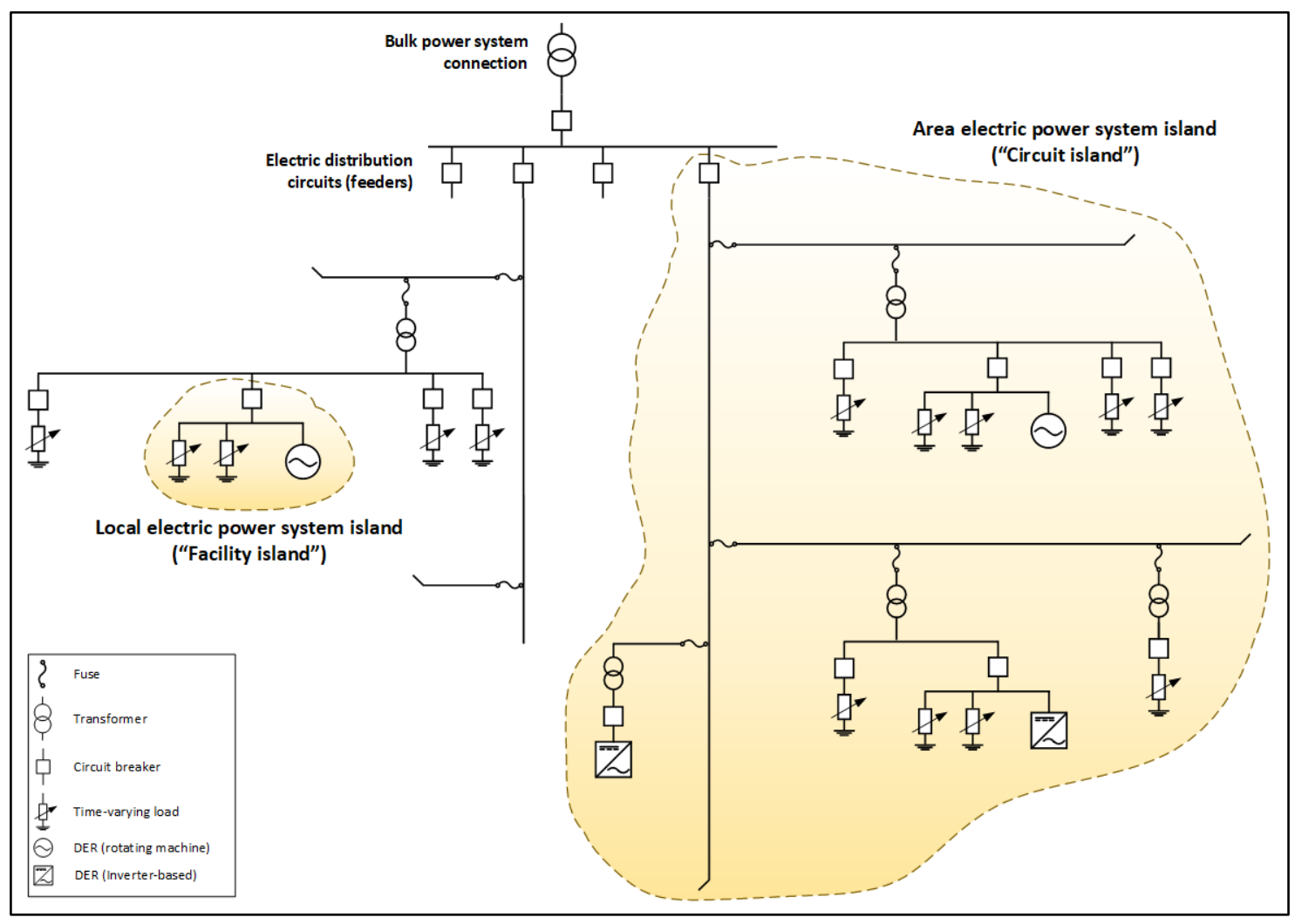

Figure 19. Two configurations of intentional islands

A facility island is typically installed to serve the needs of a single customer or a single set of customers. In such a case, the considerations for the interconnection of the facility island are generally the same as for any other DER, with the addition of specific technical requirements for connection and disconnection from the electric system. The list of stakeholders in such an interaction is generally limited to the area EPS operator and the DER/intentional island operator and/or owner. 
If, however, the intentional island is intended to serve the needs of many customers, or if the scope of the intentional island includes portions of the area EPS, as in the case of the "circuit island" shown in Figure 19, additional considerations must be evaluated and there may be additional stakeholders who should participate in the discussions.

IEEE Std 1547.4 is a guide for the design, operation, and integration of intentional islands. This document lists some specific considerations during each phase in the implementation of an intentional island. The considerations include the determination of the desired capabilities of the intentional island; agreements between the DER owner/operator and the area EPS operator for operational control of the intentional island; and the determination of other customers' loads that the intentional island must carry, including the presence of any critical loads, specific technical considerations for maintaining protective relay coordination, and voltage and frequency in islanded mode (IEEE 2011). 


\section{Step 3: Maintaining and Revising the Interconnection Rule}

Once the interconnection rule has been developed or updated, it is critical to monitor its implementation and impact from both the process and technical standpoints. Often, informative diagrams of interconnection processes and screens are included in the rule. The collaborative development of these diagrams from the rule can be helpful to the implementation as well as the validation of the functional accuracy of existing processes. Additionally, as new DER technology classes emerge, AGIRs will be required to address the challenges associated with integrating these resources into the grid. This will likely entail frequent revisions of technical requirements for interconnecting DERs in the context of technical standards such as IEEE Std 1547-2018. This section also addresses additional considerations for technology changes and updates.

\subsection{Subprocess Data Collection}

Tracking individual interconnection applications through the entirety of the interconnection process will offer insight into the types of subprocess data useful to include in the measurement plan. Underlying subprocess metrics, such as the depth and duration of screen queues, can identify potential root causes. Tracking applications is the subject of the next section, which focuses on process mapping and visualization.

Data for process analysis include interconnection queue data, subprocess cycle time, and total process cycle time. Many tools and techniques can be incorporated to visualize process workflow and to identify redundancy and inefficiencies across all stages of the interconnection process. 


\subsection{Process Analysis}

Process analysis is the integration and application of these mappings, functional diagrams, and subprocess measures to determine the added value or benefit of each major step or phase of the procedure. Further, linking regular delays, consumer complaints, and missed time limits, for example, could lead stakeholders to make previously unidentified improvements.

A primary objective of process analysis is to identify value-added and non-value-added activities. Identifying and eliminating bottlenecks is critical and is crucial to increasing process capacity (throughput) while reducing time and cost. Symptoms or consequences of bottlenecks include process starvation and activity blocking. Starvation occurs when a downstream activity is idle, with no inputs to process, because of upstream delays (bottlenecks). Blocking or congestion occurs when an activity becomes idle because the next activity is not ready to take it.

Analyzing timelines, work-in-process inventories (i.e., queues), and handoffs can reveal opportunities for improvement, including identifying process bottlenecks. Likewise, high-value but under-resourced tasks can be identified and highlighted for resource allocation. An evaluation of the queue size or work-in-process buffer volumes can also point to resource imbalances. If these factors are variable or changing, it might be effective to introduce flexibility by outsourcing certain activities. Evaluating the process flow diagram interconnections - that is, the arrows between steps - as inputs and outputs can allow the process owner and analyst to evaluate rework. If downstream processes are rejecting or otherwise returning material (such as interconnection application forms), downstream requirements or specifications might be unclear, or an opportunity for better instruction might exist.

\subsection{Requirements for Distributed Energy Resource System Modifications and Maintenance}

Because DER system components require maintenance or replacement over time, AGIRs should address how these upgrades will be handled in the context of IEEE Std 1547-2018. Cataloguing 
DER assets, including anticipated retirement/replacement of major systems such as inverters, will allow both distribution systems operators and BPS coordinators to anticipate and plan for more grid-friendly distributed resources. Utility procedures and interconnection agreements typically account for how retirement/replacement are managed by the DER owner; however, providing guidance on this issue in the rule, with the benefit of the stakeholder process, ensures safe and reliable operation.

\subsection{Considerations for Step 3 Activities}

In Step 1, this guide recommends that stakeholders assess goals and primary drivers. The conversion of these stakeholder requirements and primary drivers into KPIs and other critical metrics can be very useful for evaluating the efficiency of the interconnection rule or procedure. KPIs can be tracked and compared to historical or expected values, both to describe interconnection rule performance and to identify instances where implementation deviates from expectations to prompt corrective action. Although underlying subprocess metrics, such as depth and duration of screen queues, can identify potential root causes, a KPI combines data from multiple points to provide an overall context of implementation "health." Application cost and time in process are example KPIs.

Feedback and renewal of the interconnection procedure process (feedback loop in Figure 20) could be triggered by several factors. The most apparent is revision to industry standards that are foundational to the interconnection procedure, such as future updates to IEEE Std 1547-2018. Changes to the goals and drivers identified in Step 1 and Step 2 might also justify a revision. Additionally, sustained or consistently poor performance of KPIs or subprocess measures could indicate deficiencies that can be remedied only through revision to the rule or procedure.

\section{INTERCONNECTION PROCEDURE RULEMAKING PROCESS}

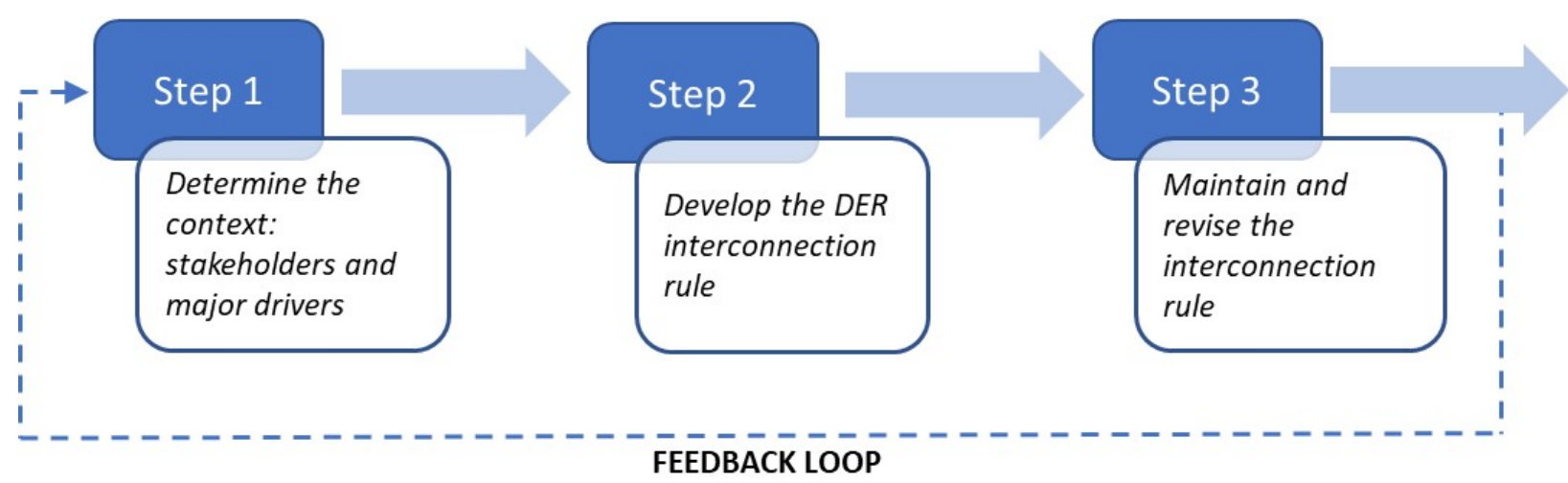

Figure 20. Feedback and renewal of interconnection rulemaking process 


\section{Conclusion}

AGIRs need to be well informed of DER capabilities that can help address technical requirements, market trends, and policy goals. Interconnection processes and technical issues often overlap; the two are not easily segregated, and they are often considered and evaluated concurrently within the context of interconnection rulemaking. Accordingly, this document addressed both the technical issues and related process considerations, including the interdependencies that might arise.

Although this document describes a three-step process for developing and updating interconnection rules, the AGIR and stakeholders to the process should keep the following considerations in mind throughout the process:

- New or updated rules should allow for the use of latest DER capabilities (even if they are to be used in the future) as required under IEEE 1547-2018.

- AGIRs should undertake a robust stakeholder identification process to ensure that all parties relevant to the effort are involved and that sufficient time for stakeholder discussion and resolution of issues is allotted.

The internal motivations for updating the rule, agreed upon by all stakeholders in Step 1, should guide the overall effort. 


\section{References}

Barbose, Galen, Naïm Darghouth, Ben Hoen, and Ryan Wiser. 2018. Income Trends of Residential PV Adopters: An Analysis of Household-Level Income Estimates. Berkeley, CA: Lawrence Berkeley National Laboratory. https://etapublications.lbl.gov/sites/default/files/income trends of residential pv adopters final 0.pdf.

Beaty, H. Wayne, and Donald G. Fink. 2007. Standard Handbookfor Electrical Engineers. 15th ed. New York: McGraw-Hill.

Cory, Karlynn, Brendan Canavan, and Ronald Koenig. 2009. "Power Purchase Agreement Checklist for State and Local Governments." Golden, CO: National Renewable Energy Laboratory. https:/www.nrel.gov/docs/fy10osti/46668.pdf

Coughlin, J., Jennifer Grove, Linda Irvine, Janet F. Jacobs, Sarah Johnson Phillips, Alexandra Sawyer, and Joseph Wiedman. 2012. A Guide to Community Shared Solar: Utility, Private, and Nonprofit Project Development. Golden, CO: National Renewable Energy Laboratory. https://www.nrel.gov/docs/fy12osti/54570.pdf.

Cruz, Nuno, Sanford V. Berg, and Rui Cunha Marques. 2011. "Managing Public Utilities: The American Way." Gainesville, FL: University of Florida, Department of Economics.

Database of State Incentives for Renewables \& Efficiency (DSIRE). 2016. "Interconnection Standards for Small Generators; Program Overview." https://programs.dsireusa.org/system/program/detail/2774.

Department of Energy (DOE). 2021. "Low-Income Community Energy Solutions." https://www.energy.gov/eere/slsc/low-income-community-energy-solutions.

Dugan, Roger C., Mark F. McGranaghan, Surya Santoso, and H. Wayne Beaty. 2003. Electrical Power Systems Quality. Second Edition. New York: McGraw-Hill.

Federal Energy Regulatory Commission (FERC). 2013. Order No. 792, Small Generator Interconnection Agreements and Procedures, November 22, 2013. https://www.ferc.gov/whatsnew/comm-meet/2013/112113/E-1.pdf.

Gallucci, Maria. 2019 "Energy Equity: Bringing Solar Power to Low-Income Communities." Yale Environment 360, April 4, 2019. https://e360.yale.edu/features/energy-equity-bringingsolar-power-to-low-income-communities.

Hawaiian Electric Companies (HECO). 2017. Hawaiian Electric Companies' PSIPs Update Report: Book 1 of 4. Honolulu, Hawaii.

https://dms.puc.hawaii.gov/dms/DocumentViewer?pid=A1001001A16L27B50409B58212.

Ingram, Michael, Rasel Mahmud, and David Narang. 2021. Informative Background on the Interoperability Requirements in IEEE Std 1547-2018. Golden, CO: National Renewable Energy Laboratory. NREL/TP-5D00-77959. https://www.nrel.gov/docs/fy21osti/77959.pdf. 
Institute of Electrical and Electronics Engineers (IEEE). 2011. IEEE Recommended Practice for Interconnecting Distributed Resources with Electric Power Systems Distribution Secondary Networks. https://standards.ieee.org/standard/1547 6-2011.html.

- 2018. IEEE Standard for Interconnection and Interoperability of Distributed Energy Resources with Associated Electric Power Systems Interfaces. https://standards.ieee.org/standard/1547-2018.html.

International Renewable Energy Agency (IRENA). 2015. Renewable Energy Target Setting. Abu Dhabi, United Arab Emirates. Accessed October 2019. https://www.irena.org/documentdownloads/publications/irena_re target_setting_2015.pdf.

Interstate Renewable Energy Council (IREC). 2019. Model Interconnection Procedures. Latham, New York.

Michigan Public Service Commission. 2018. Michigan Public Service Commission Annual Report 2017. Lansing, Michigan. Accessed October 2019.

https://www.michigan.gov/documents/mpsc/MPSC Annual_Report with_Cover_Letter 2017 F inal 616391 7.pdf.

Minnesota Public Utilities Commission (MPUC). 2019. "Distributed Generation in Minnesota." https://mn.gov/puc/energy/distributed-energy/data/.

Murphy, Caitlin, Eliza Hotchkiss, Kate Anderson, Clayton Barrows, Stuart Cohen, Sourabh Dalvi, Nick Laws, Jeff Maguire, Gord Stephen, and Eric Wilson. 2020. Adapting Existing Energy Planning, Simulation, and Operational Models for Resilience Analysis. Golden, CO: National Renewable Energy Laboratory. NREL/TP-6A20-74241. https://www.nrel.gov/docs/fy20osti/74241.pdf

Narang, David, Michael Ingram, Andy Hoke, Akanksha Bhat, and Shazreen Meor Danial. 2020. Clause-by-Clause Summary of Requirements in IEEE Standard 1547-2018. Golden, CO: National Renewable Energy Laboratory. https://www.nrel.gov/docs/fy20osti/75184.pdf.

National Association of Regulatory Utility Commissioners (NARUC). 2020. Resolutions Passed by NARUC Board of Directors 2020 Winter Policy Summit. Washington, D.C. Accessed July 2021. https://pubs.naruc.org/pub/4C436369-155D-0A36-314F-8B6C4DE0F7C7

National Electrical Manufacturers Association (NEMA). 2016. "ANSI C84.1-2016 American National Standard for Electric Power Systems and Equipment_-Voltage Ratings (60 Hertz).”

Nayar, Vineet. 2014. “A Shared Purpose Drives Collaboration.” Harvard Business Publishing.

North American Electric Reliability Corporation (NERC). 2007. Definition of “Adequate Level of Reliability. ” Princeton, NJ. https://www.nerc.com/docs/pc/Definition-of-ALR-approved-atDec-07-OC-PC-mtgs.pdf. 
- 2013. Performance of Distributed Energy Resources During and After System Disturbance: Voltage and Frequency Ride-Through Requirements. Princeton, NJ.

https://www.nerc.com/pa/RAPA/ra/Reliability\%20Assessments\%20DL/IVGTF17_PC_FinalDra ft_December_clean.pdf.

- 2018. Reliability Functional Model: Function Definitions and Functional EntitiesVersion 5.1. Princeton, NJ. https://www.nerc.com/pa/Stand/Functional\%20Model\%20Advisory\%20Group\%20DL/Function al Model V5.1 clean 201807.pdf.

- 2020. Reliability Guideline: Bulk Power System Reliability Perspectives on the Adoption of IEEE 1547-2018. Atlanta, GA.

Paaso, Esa, Joseph Svachula, and Shay Bahramirad. 2015. Planning and Operations of the Utility of the Future in Illinois. The Electricity Journal 28 (10).

Rickerson, Wilson, Jonathan Gillis, and Marisa Bulkeley. 2019. The Value of Resilience for Distributed Energy Resources: An Overview of Current Analytical Practices. Washington, D.C.: National Association of Regulatory Utility Commissioners. https://pubs.naruc.org/pub/531AD059-9CC0-BAF6-127B-99BCB5F02198.

Roberts, Henry Martyn. 1998. Robert's Rules of Order. New York, NY: Berkley Publishing Corporation.

Ropp, Michael. 2019. Guide to the IEEE 1547-2018 Standard and its Impacts on Cooperatives. Arlington, VA: National Rural Electric Cooperative Association. https://www.cooperative.com/programs-services/bts/Documents/Reports/NRECA-Guide-toIEEE-1547-2018-March-2019.pdf.

Sink, D. Scott. 1989. Planning and Measurement in Your Organization of the Future. Norcross, $\mathrm{Ga}$ : Institute of Industrial Engineers.

Smart Energy Consumer Collaborative (SECC). 2019. "Distributed Resources: Meeting Consumer Needs.” December 2019.

Sunter, Deborah A., Sergio Castellanos, and Daniel M. Kammen. 2019. "Disparities in Rooftop Photovoltaics Deployment in the United States by Race and Ethnicity." Nature Sustainability. https://www.nature.com/articles/s41893-018-0204-Z.pdf.

The White House. 2013. "Presidential Policy Directive 21: Critical Infrastructure Security and Resilience (PPD-21).” February 12, 2013. https://obamawhitehouse.archives.gov/the-pressoffice/2013/02/12/presidential-policy-directive-critical-infrastructure-security-and-resil.

Torres, Juan, and Nick Laws. 2018. "Energy Resilience Through Grid Modernization and Renewables Integration." Presented at the Critical Infrastructure Resilience Workshop, Washington, D.C., December 7, 2018. https://www.nrel.gov/docs/fy19osti/72884.pdf. 
Zitelman, Kiera. 2020. Advancing Electric System Resilience with Distributed Energy Resources: A Review of State Policies. Washington, D.C.: National Association of Regulatory Utility Commissioners. https://pubs.naruc.org/pub/ECD7FAA5-155D-0A36-31055CE60957C305. 


\section{Bibliography}

Asmus, Peter. 2018. "Utilities Are Accelerating Microgrid Investments in Innovative and Strategic Ways.” GreenBiz, December 2018. Accessed April 2020.

https://www.greenbiz.com/article/utilities-are-accelerating-microgrid-investments-innovativeand-strategic-ways.

Bahramirad, Shay. 2019. "Utilities Are Getting In on the Microgrid Action to Make Communities More Resilient." GreenBiz, September 2019. Accessed April 2020. https://www.greenbiz.com/article/utilities-are-getting-microgrid-action-make-communitiesmore-resilient.

Database of State Incentives for Renewables \& Efficiency (DSIRE). 2017. "Renewable Portfolio Standards (RPS) with Solar or Distributed Generation Provisions,” NC Clean Energy Technology Center. http://ncsolarcen-prod.s3.amazonaws.com/wpcontent/uploads/2019/07/RPS carveout 4.pdf.

Lee, J. Irving. 1954. "Procedure for Coercing Agreement." Harvard Business Review (HBR) 54108.

New York State Department of Public Services. 2020. "Distributed Generation Information." http://www3.dps.ny.gov/W/PSCWeb.nsf/All/DCF68EFCA391AD6085257687006F396B?Open Document.

New York State Public Services Commission. 2019. New York State Standardized Interconnection Requirements and Application Process For New Distributed Generators and Energy Storage Systems 5 MW or Less Connected in Parallel with Utility Distribution Systems. New York, NY.

http://www3.dps.ny.gov/W/PSCWeb.nsf/96f0fec0b45a3c6485257688006a701a/dcf68efca391ad 6085257687006f396b/\$FILE/December\%202019\%20SIR\%20-\%20FINAL\%20-\%20Clean.pdf.

PJM. 2012. "FERC Jurisdiction over Distribution Interconnections and Required PJM Involvement." https://www.pjm.com/-/media/committees-groups/taskforces/nemstf/20120206/20120206-jurisdictional-chart.ashx.

Rosier, Michelle. 2018. "Regulatory Perspective: IEEE 1547 Revision and DER Interconnection Standards.” Presented at the Spring 2018 Joint CREPC-WIRAB Meeting, April 20, 2018. https:/www.nrel.gov/grid/ieee-standard-1547/assets/pdfs/regulatory-perspective-michellerosier.pdf.

Schwartz, Lisa. 2018. "Overview of Integrated Distribution Planning Concepts and State Activity." Presented at the Mid-Atlantic Distributed Resource Initiative, March 13, 2018. https://emp.lbl.gov/publications/overview-integrated-distribution.

Seguin, Rich, Jeremy Woyak, David Costyk, Josh Hambrick, and Barry Mather National. 2016. High-Penetration PV Integration Handbook for Distribution Engineers. Golden, CO: National Renewable Energy Laboratory. NREL/TP-5D00-63114. https://www.nrel.gov/docs/fy16osti/63114.pdf. 
U.S. Department of Energy. 2016. Integrated Distribution Planning. Washington, D.C. https://www.energy.gov/oe/downloads/integrated-distribution-planning-report-august-2016.

Wood Mackenzie and Solar Energy Industries Association. 2019. U.S. Solar Market Insight. Washington, D.C. https://www.seia.org/us-solar-market-insight. 